Research Article

\title{
An acoustic study of contextual tonal variation in Tianjin Mandarin
}

\author{
Qian $\mathrm{Li}^{\mathrm{a}, *}$, Yiya Chen ${ }^{\mathrm{a}, \mathrm{b}}$ \\ a Leiden University Center for Linguistics, Postbus 9515, 2300 RA, Leiden, The Netherlands \\ ${ }^{\mathrm{b}}$ Leiden Institute for Brain and Cognition, Postbus 9515, 2300 RA, Leiden, The Netherlands
}

\section{A R T I C L E I NFO}

\section{Article history:}

Received 22 August 2013

Received in revised form

18 October 2015

Accepted 20 October 2015

\section{Keywords:}

Tonal variation

Tone sandhi

Tonal coarticulation

Tianjin Mandarin

\begin{abstract}
A B S T R A C T
The fo realization of lexical tones is known to vary greatly due to contextual tonal variation processes such as tone sandhi and tonal coarticulation. This study set out to investigate the fo variability induced by these two different sources with well-controlled acoustic data from Tianjin Mandarin. Tianjin Mandarin is known for its complex patterns of tonal variation over disyllabic constituents, as well as for the conflicting directionality of sandhi alternations and possible iterative application of disyllabic sandhi rules over trisyllabic constituents. Previous studies on Tianjin tone sandhi have often been based on impressionistic descriptions of speech produced by speakers of older generations. In this study, we investigated the $f 0$ realization of disyllabic and trisyllabic tonal sequences in Tianjin Mandarin produced by younger speakers (born in the 1980s). Through examining f0 variation of lexical tones as a function of different following tones, we observed an interesting anticipatory raising effect of the lexical low-falling tone (T1). Furthermore, we confirmed three tonal sequences with tone sandhi changes: (1) two low-falling tones (T1T1), (2) a high-falling tone followed by a low-falling tone (T4T1), and (3) two low-dipping tones (T3T3). These disyllabic tone sandhi patterns, however, were not consistently observed within trisyllabic sequences, as claimed in the literature. Specifically, while T3T3 showed sandhi application regardless of its position within a trisyllabic sequence, T1T1 and T4T1 sequences showed sandhi changes only when they were right aligned. Last but not least, no tonal neutralization was observed over any of the sandhi processes. Rather, we argue that T3T3 is a near-merger sandhi case, while T1T1 and T4T1 can be classified as no-merger sandhi sequences.
\end{abstract}

(c) 2015 Elsevier Ltd. All rights reserved.

\section{Introduction}

It is known that the $f 0$ realization of lexical tones varies extensively in connected speech. At a global level, $f 0$ can vary due to the overall discourse prosody in which the tone-bearing lexical item is produced. At a more local level, the fo realization of a lexical tone can be further affected by its neighboring tones (see e.g., Chen, 2012 for a review). One well-noted local contextual effect is tone sandhi, which is often described as the phonological change of lexical tones (Chen, 2000; also see Zhang, 2010 for a review). Another local contextual effect is tonal coarticulation, which is traditionally defined as phonetically minor $f 0$ adjustments to preceding or following tones (see $\mathrm{Xu}, 2001$ for a review). Both processes cause changes in the fo realization of a lexical tone, so that the resulting $f 0$ contour may deviate to varying degrees from the canonical fo shape of the tone produced in isolation. While there has been general agreement on the difference between tonal coarticulation and tone sandhi to account for contextual tonal variation, there is little consensus or research effort on how exactly or whether the wide range of $f 0$ deviations can be categorized as a function of these two distinct processes.

In this study, we aimed to address this issue through directly comparing these two types of tonal variation. Our empirical base is Tianjin Mandarin, a Northern Mandarin dialect spoken in the urban areas of Tianjin, a metropolis in northern China. Tianjin Mandarin presents an interesting test case on tonal variation, further understanding of which will shed light on how different tonal variation processes intertwine to determine the $f 0$ realization of lexical tones. The dialect is known for its complex tone sandhi patterns over disyllabic constituents. Over trisyllabic constituents, some tone sandhi rules have been argued to apply only to the leftmost two syllables, while others only to the rightmost two syllables, regardless of the morpho-syntactic structures. Furthermore, some sandhi

\footnotetext{
* Corresponding author. Tel.: +3171527 3316

E-mail address: q.li@hum.leidenuniv.nl (Q. Li).
} 
rules are claimed to apply iteratively, i.e., over derived contexts of the first round of sandhi application. These two properties are together known as the "paradox" in Tianjin tone sandhi (e.g., Chen, 2000).

It is important to note that although tonal variation in Tianjin Mandarin has been extensively studied, most were based on impressionistic data. In a recent acoustic study, Zhang and Liu (2011) examined tonal coarticulation of disyllabic items but did not compare them to the previously claimed tone sandhi patterns. This makes it impossible to evaluate directly how tonal variation due to different sources may differ. Furthermore, despite the potentially significant implications of the Tianjin Mandarin tone sandhi "paradox" on our theoretical modeling of tonal variation, no experimental work has been done on trisyllabic tone sandhi in Tianjin Mandarin. Pilot results in Li and Chen (2012) raised serious doubts on the tonal variation patterns of trisyllabic sequences reported in the literature (Chen, 2000 and references therein).

The specific goal of this study therefore was to collect data from a well-controlled acoustic experiment and investigate (1) how lexical tones are realized with varying $f 0$ contours in disyllabic domains without pre-exclusion of any tonal sequence claimed to involve tone sandhi processes; and (2) whether disyllabic tone sandhi alternations can be observed in trisyllabic constituents, with particular focus upon the issue of directionality and iterativity of sandhi application. By doing so, we hope to arrive at a better understanding of tonal realization in Tianjin Mandarin, which, in turn, would help to further refine a general theory of tonal variation.

\subsection{Lexical tones of Tianjin Mandarin in isolation}

Although Tianjin Mandarin has a very similar segmental structure to Standard Chinese, the dialect differs significantly from Standard Chinese in terms of the tonal system (Han, 1993; Wee, Yan, \& Chen, 2005). There are four lexical tones in Tianjin Mandarin. Fig. 1 illustrates the $f 0$ realization of the four lexical tones elicited in isolation. All $f 0$ contours were plotted based on 50 samples with different segmental structures for each tone, produced by a male native speaker in his 20s at the time of recording (born in 1983). $f 0$ contours were time-normalized by taking 20 points in the rhyme part of each syllable with equal time interval. The $f 0$ values were normalized by converting them to speaker-specific $z$-scores (Rose, 1987) with the formula: $z=\frac{f 0_{x}-f 0_{m e a n}}{f 0_{s p}}$. $\left(f 0_{x}\right.$ : the observed $f 0$ value in $\mathrm{Hz} ; \mathrm{fO}_{\text {mean }}$ : the mean $\mathrm{fO}$ value of the speaker in $\mathrm{Hz}$; $f 0_{S D}$ : the standard deviation of $f 0$ value of the $\mathrm{Speaker}$ in $\mathrm{Hz}$.)

As can be seen from Fig. 1, Tone 1 is a low-register falling tone, with a pitch contour that falls from the middle to the lower end of the speaker's pitch range. Tone 2 is a high-register rising tone, whose pitch contour rises from the middle to the upper end of the pitch range. Tone 3 is a low-register dipping tone, which falls slightly from the lower pitch range, stays at the bottom and then rises to the mid pitch range of the speaker. Tone 4 is a high-register falling tone which falls from the upper end to the mid pitch range.

Table 1 summarizes the annotations adopted in different studies. Strictly speaking, no annotation system listed in Table 1 accurately reflects the fo contours plotted in Fig. 1. This discrepancy is in part an indication of the considerable variation in lexical tone production that exists both within and across speakers of the same generation as well as across speakers of different generations. Despite the variability, the basic fo patterns of the four lexical tones are rather consistent at a more abstract level.

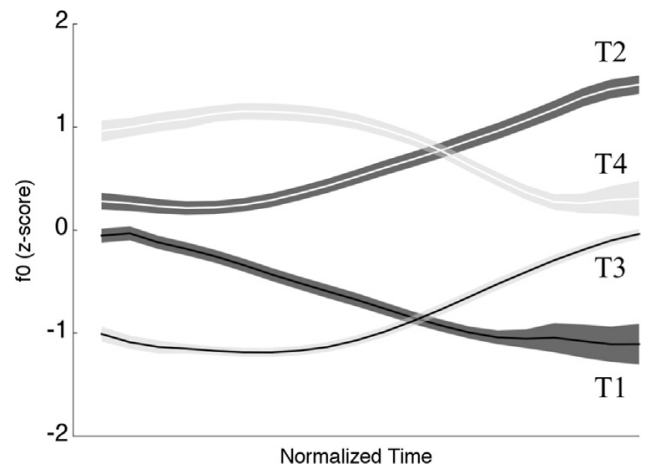

Fig. 1. Four lexical tones in Tianjin Mandarin produced in isolation (with normalized time). Lines stand for the mean. Gray areas stand for \pm 1 standard error of the mean.

Table 1

Transcriptions of the four lexical tones in Tianjin Mandarin in different studies.

\begin{tabular}{lllll}
\hline T1 & T2 & T3 & T4 & \\
\hline $\mathrm{L}$ & $\mathrm{H}$ & $\mathrm{R}(\mathrm{LH})$ & $\mathrm{F}(\mathrm{HL})$ & $\begin{array}{l}\text { For e.g., Chen (2000), Wee et al. (2005), } \\
\text { Hyman (2007) }\end{array}$ \\
$\mathrm{LL}$ & $\mathrm{HH}$ & $\mathrm{HL}$ & $\begin{array}{l}\text { For e.g., Wang and Jiang (1997); Wang } \\
\text { (2002); Ma (2005) }\end{array}$ \\
21 & 45 & 213 & 53 & $\begin{array}{l}\text { For e.g., Li and Liu (1985), Hung (1987), Tan } \\
\text { (1987), Zhang (1987) and Han (1993) }\end{array}$ \\
211 & 455 & 113 & 553 & For e.g., Shi (1986) \\
41 & 34 & 12 & 52 & For e.g., Zhang and Liu (2011) \\
\hline
\end{tabular}




\subsection{Tonal variation in connected speech in Tianjin Mandarin}

In connected speech, tonal variation abounds in Tianjin Mandarin. Of our interest are the two processes that have been described in the literature to extensively influence the $f 0$ contour of a lexical tone within a local tonal context: tonal coarticulation and tone sandhi.

\subsubsection{Tonal coarticulation}

Tonal coarticulation has been reported in many East Asian contour-tone languages, such as Thai (e.g., Palmer, 1969; Abramson, 1979; Gandour et al., 1993; Gandour, Potisuk \& Dechongkit, 1994; Gandour et al., 1996; Potisuk, Gandour \& Harper, 1997; Zsiga \& Nitisaroj, 2007), Vietnamese (e.g., Han \& Kim, 1974; Brunelle, 2009), Standard Chinese (e.g., Shen, 1990; Xu, 1994; Xu, 1997; Kochanski, Shih \& Jing, 2003), Taiwanese (e.g., Peng, 1997; Wang, 2002), and Malaysian Hokkien (e.g., Chang \& Hsieh, 2012). Despite the differences among languages, two types of tonal coarticulation have been commonly attested: the left-to-right carryover tonal coarticulation and the right-to-left anticipatory tonal coarticulation.

Carryover tonal coarticulation refers to the effect that the production of the first tone has on its following tone in a disyllabic tonal sequence. Carryover effects are generally assimilatory in nature (e.g., Han \& Kim, 1974; Abramson, 1979; Shen, 1990; Gandour et al., 1994; Potisuk et al., 1997; Xu, 1997; Brunelle, 2009). Therefore, the high f0 offset of the first tone raises the f0 onset of the second tone, while the low f0 offset lowers the following onset. Such tonal coarticulation patterns have been observed consistently across languages regardless of the identity of the first tone. Due to the carryover effects, the onset of the second tone usually varies greatly. The influence from the preceding tone can be extended well into the first half or the entire second tone, although the magnitude of the influence decreases over time (e.g., Gandour et al., 1993, 1994; Potisuk et al., 1997; Xu, 1997; Brunelle, 2009).

The cross-linguistic carryover effects have been reported for Tianjin Mandarin in Zhang and Liu (2011). Specifically, they argued that three tones in Tianjin Mandarin are subject to the carryover effects, i.e., T2, T3, and T4. The low-falling tone (T1), however, was claimed to resist the carryover effects from any preceding tone.

In contrast to carryover effects, anticipatory tonal coarticulation refers to the effect of a following lexical tone on the production of its preceding tone. Anticipatory effects are mainly dissimilatory in nature (but see Shih and Konchanski, 2000 for reported assimilatory anticipatory effects in Standard Chinese), and are usually restricted to a limited number of triggering contexts. The magnitude and the temporal extent of their influence are also much less (e.g., Gandour et al., 1994; Potisuk et al., 1997; Xu, 1997; but see Chang \& Hsieh, 2012 for more powerful anticipatory effects reported for Malaysian Hokkien). In a disyllabic tonal sequence, the anticipatory effects seem to be triggered only by a following low tone (e.g., Gandour et al., 1994 and Xu, 1997 for Thai and Mandarin, respectively). In most cases, anticipatory effects on the first tone are also rather negligible and localized to the offset of the preceding tone (e.g., Potisuk et al., 1997; Xu, 1997).

In Tianjin Mandarin, only a minor anticipatory effect has been reported, which is triggered by the low-register dipping T3 (Zhang \& Liu, 2011). It is important to point out that Zhang and Liu (2011) did not examine tonal combinations that were assumed to involve tone sandhi for potential anticipatory effects. This makes our understanding of the anticipatory tonal coarticulation effects in Tianjin Mandarin possibly limited and incomplete. Given that in Tianjin Mandarin, tone sandhi is right dominant and anticipatory coarticulation is also triggered by the second syllable within a disyllabic word, we think it is particularly important that we include all possible tonal combinations to shed further light on the potential differences between tonal coarticulation and tone sandhi.

\subsubsection{Tone sandhi}

Different from tonal coarticulation that is usually considered the phonetic modification of fo contours, tone sandhi, in many of the impressionistic reports, is considered to involve the categorical change of the phonological identity of a lexical tone. Much work has been done on tone sandhi in various Chinese dialects (see e.g., Chen, 2000 for an overview), among which Tianjin Mandarin is known for its complex sandhi patterns over disyllabic and trisyllabic constituents.

For disyllabic sequences, most previous studies on Tianjin Mandarin have identified four disyllabic tone sandhi rules (e.g., Li \& Liu, 1985; Hung, 1987; Tan, 1987; Zhang, 1987; Chen, 2000; J. Wang, 2002; Ma \& Jia, 2006; Hyman, 2007), as shown in Rules (1)-(4), where the tones were transcribed with features adopted from Chen (2000).

(1) $\mathrm{T} 1+\mathrm{T} 1(\mathrm{~L}+\mathrm{L}) \rightarrow \mathrm{T} 3+\mathrm{T} 1(\mathrm{LH}+\mathrm{L})$

(2) $\mathrm{T} 3+\mathrm{T} 3(\mathrm{LH}+\mathrm{LH}) \rightarrow \mathrm{T} 2+\mathrm{T} 3(\mathrm{H}+\mathrm{LH})$

(3) $\mathrm{T} 4+\mathrm{T} 4(\mathrm{HL}+\mathrm{HL}) \rightarrow \mathrm{T} 1+\mathrm{T} 4(\mathrm{~L}+\mathrm{HL})$

(4) $\mathrm{T} 4+\mathrm{T} 1(\mathrm{HL}+\mathrm{L}) \rightarrow \mathrm{T} 2+\mathrm{T} 1(\mathrm{H}+\mathrm{L})$

Rules (1)-(3) have been attributed to tonal dissimilation due to the Obligatory Contour Principle, while Rule (4) is attributed to Tonal Absorption (Chen, 2000). With sociolinguistic data, Lu (1997) proposes that Rule (1) has undergone some diachronic changes. A new pattern of that sandhi change, i.e., $T 1+T 1(L+L) \rightarrow T 2+T 1(H+L)$, has been observed in the speech of the younger generation. In addition, Rule (4) has been reported to become "obsolete" in the speech of the younger generation (Liu \& Gao, 2003). More recently, Wee et al. (2005) argued that there are two more sandhi rules in Tianjin Mandarin, where T3 changes to T1 before either T2 or T4 as shown in Rules (5) and (6).

(5) $\mathrm{T} 3+\mathrm{T} 2(\mathrm{LH}+\mathrm{H}) \rightarrow \mathrm{T} 1+\mathrm{T} 2(\mathrm{~L}+\mathrm{H})$

(6) $\mathrm{T} 3+\mathrm{T} 4(\mathrm{LH}+\mathrm{HL}) \rightarrow \mathrm{T} 1+\mathrm{T} 4(\mathrm{~L}+\mathrm{HL})$ 
What is shared among all the impressionistic studies is that tone sandhi involves the categorical change of one lexical tone to another within the native lexical tonal system. However, recent experimental data suggest that in Tianjin Mandarin, tonal neutralization might not be involved at all in disyllabic tone sandhi (Zhang \& Liu, 2011; Li \& Chen, 2012).

For trisyllabic sequences, the tone sandhi situation becomes more complicated. Of all 64 tonal combinations of trisyllabic sequences, 27 have been claimed to involve sandhi based on the four commonly accepted disyllabic sandhi rules (e.g., Li \& Liu, 1985; Chen, 2000; Ma, 2005; but see Wee et al., 2005 for more trisyllabic sequences that undergo sandhi changes).

Among the 27 combinations, 20 have been referred to as simple applications, where only one disyllabic sandhi rule could possibly apply. These disyllabic patterns have been argued to apply consistently within a trisyllabic domain, regardless of the location where the disyllabic combinations occur. For example, T1T1 sandhi is claimed to apply over both T1T1T2 and T2T1T1.

The other seven cases (7)-(13) have been claimed to involve iterativity and directionality issues of sandhi applications (e.g., Li \& Liu, 1985; Chen, 2000; Ma, 2005). Specifically, (7)-(11) have been claimed to involve iterative sandhi rule application, due to a newly-derived sandhi context after the first round of sandhi application. For example, in the sequence T3T1T1 (10), the first T1 is claimed to change to T3, which results in an intermediate stage T3T3T1 where T3T3 is again a possible sandhi context, leading to the final output as T2T3T1.

\begin{tabular}{llllll}
\hline & Underlying pattern & & 1st round of application & 2nd round of application \\
\hline$(7)$ & $\mathrm{T} 3+\mathrm{T} 3+\mathrm{T} 3(\mathrm{LH}+\mathrm{LH}+\mathrm{LH})$ & $\rightarrow$ & $\mathrm{T} 2+\mathrm{T} 3+\mathrm{T} 3(\mathrm{H}+\mathrm{LH}+\mathrm{LH})$ & $\rightarrow$ & $\mathrm{T} 2+\mathrm{T} 2+\mathrm{T} 3(\mathrm{H}+\mathrm{H}+\mathrm{LH})$ \\
$(8)$ & $\mathrm{T} 4+\mathrm{T} 4+\mathrm{T} 1(\mathrm{HL}+\mathrm{HL}+\mathrm{L})$ & $\rightarrow$ & $\mathrm{T} 1+\mathrm{T} 4+\mathrm{T} 1(\mathrm{~L}+\mathrm{HL}+\mathrm{L})$ & $\rightarrow$ & $\mathrm{T} 1+\mathrm{T} 2+\mathrm{T} 1(\mathrm{~L}+\mathrm{H}+\mathrm{L})$ \\
$(9)$ & $\mathrm{T} 4+\mathrm{T} 4+\mathrm{T} 4(\mathrm{HL}+\mathrm{HL}+\mathrm{HL})$ & $\rightarrow$ & $\mathrm{T} 4+\mathrm{T} 1+\mathrm{T} 4(\mathrm{HL}+\mathrm{L}+\mathrm{HL})$ & $\rightarrow$ & $\mathrm{T} 2+\mathrm{T} 1+\mathrm{T} 4(\mathrm{H}+\mathrm{L}+\mathrm{HL})$ \\
$(10)$ & $\mathrm{T} 3+\mathrm{T} 1+\mathrm{T} 1(\mathrm{LH}+\mathrm{L}+\mathrm{L})$ & $\rightarrow$ & $\mathrm{T} 3+\mathrm{T} 3+\mathrm{T} 1(\mathrm{LH}+\mathrm{LH}+\mathrm{L})$ & $\rightarrow$ & $\mathrm{T} 2+\mathrm{T} 3+\mathrm{T} 1(\mathrm{H}+\mathrm{LH}+\mathrm{L})$ \\
$(11)$ & $\mathrm{T} 1+\mathrm{T} 4+\mathrm{T} 4(\mathrm{~L}+\mathrm{HL}+\mathrm{HL})$ & $\rightarrow$ & $\mathrm{T} 1+\mathrm{T} 1+\mathrm{T} 4(\mathrm{~L}+\mathrm{L}+\mathrm{HL})$ & $\rightarrow$ & \\
$(12)$ & $\mathrm{T} 1+\mathrm{T} 1+\mathrm{T} 1(\mathrm{~L}+\mathrm{L}+\mathrm{L})$ & $\rightarrow$ & $\mathrm{T} 1+\mathrm{T} 3+\mathrm{T} 1(\mathrm{~L}+\mathrm{LH}+\mathrm{L})$ & & \\
$(13)$ & $\mathrm{T} 4+\mathrm{T} 1+\mathrm{T} 1(\mathrm{HL}+\mathrm{L}+\mathrm{L})$ & $\rightarrow$ & $\mathrm{T} 4+\mathrm{T} 3+\mathrm{T} 1(\mathrm{HL}+\mathrm{LH}+\mathrm{L})$ & & \\
\hline
\end{tabular}

The seven cases here have also been argued to exemplify the directionality of tone sandhi changes. (7) and (8) have been argued to undergo sandhi processes from the left edge and (9)-(13) from the right edge. Taking the tonal sequence T1T1T1 (12) as an example. This sequence has been reported to surface as T1T3T1, which has been taken as evidence that the sandhi rule must have been applied from the right edge of the constituent instead of the left edge.

Various attempts have been made to explain the complex sandhi application in Tianjin Mandarin (e.g., Hung, 1987; Tan, 1987; Zhang, 1987; Chen, 2000; Ma, 2005; Wee et al., 2005), but no consensus has been reached. The issues of iterative and directional applications of tone sandhi in Tianjin Mandarin not only have presented great challenges to phonological theories of tonal alternation, but also have raised interesting questions regarding theories of allotone processing and learnability.

Before any attempt to address these theoretical issues is made, two problems need to be tackled with regard to the proposed trisyllabic sandhi rules. First, since the disyllabic combinations have been shown to be realized differently from what has been claimed in the literature, it is very likely that the actual realization of trisyllabic combinations might also differ from those described in previous studies. Second, the so-called iterative sandhi application proposed for some trisyllabic combinations is based on the assumption that sandhiderived tones are lexical tones within the system and there is complete neutralization of the derived and the base tones. If indeed tone sandhi in Tianjin Mandarin does not involve lexical tone neutralization, any iterative tonal change is then called into question. At this stage, we believe that well-controlled experimental data are not only needed but also crucial for our further understanding of these issues.

\section{Method}

Disyllabic tonal sequences with full combination of the four lexical tones $\left(T_{1-4} T_{1-4}\right)$ were collected to allow direct comparison of the two possible types of tonal variation, i.e., tonal coarticulation and tone sandhi in the language. To investigate further the iterativity and directionality of tone sandhi application, relevant trisyllabic sequences were also included. Subsets of the data will also provide us with evidence to shed light on the issue of tonal neutralization under sandhi changes.

\subsection{Materials}

We used real words and phrases because most of our speakers reported to have difficulties in producing nonsense sequences (see also Zhang \& Liu, 2010 for different tonal realization of nonsense words compared to real words). Two reading lists were included in this study, one for the disyllabic sequences and the other for the trisyllabic sequences.

The disyllabic reading list consisted of all 16 possible tonal combinations of the four lexical tones in Tianjin Mandarin. All stimuli are common collocations, which are arguably lexicalized in the language. For possible influence from their internal morpho-syntactic structures, we limited the structures to three different combinations: Compound (e.g., 爹妈 die "ma "parent"), Modifier+Head (e.g., 鳥它 乌 tuo ${ }^{2}$ niao ${ }^{3}$ "ostrich"), and Verb+Object (e.g., 推理 tui ${ }^{1} \mathrm{li}^{3}$ "inference"). These morpho-syntactic structures had a balanced number for each tonal combination. The choice of the stimuli was further constrained by their segmental composition. Only sonorant onsets were used for the second syllables in order to better observe the effect of contextual tonal variation and also for the ease of segmentation. 
The trisyllabic reading list included all 64 combinations of the four lexical tones. For each trisyllabic tonal combination, the sequence was either a mono-morphemic word ( $\sigma \sigma \sigma$, as mostly seen in loan words such as乌拉圭 wu ${ }^{1}$ la $^{1}$ gui " “Uraguay"; hereafter, underlines indicate the constituent structure of the sequence), or a compound or phrase with two different internal grouping patterns: $\sigma \sigma+\sigma$ (e.g., 拉 丁舞 la ${ }^{1}$ ding $^{1}$ wu $^{3}$ “Latin dance”) or $\sigma+\sigma \sigma$ (e.g., 高工资 gao ${ }^{1}$ gong $^{1} \mathrm{zi}^{1}$ “high salary"). For each structure, we included two different items. Due to the limited availability of syllables with sonorant onsets, items with obstruent onsets at the second and third syllable were also used. Most test items are very common words and phrases with an exception of a few, which nevertheless are still relatively common.

Each test item was embedded in a unique carrier sentence with the copular verb "... shi ${ }^{4} \ldots$ (' $\ldots$ is ...')." The length of each carrier sentence was within the range of 9-11 syllables as illustrated in the following example, where the target stimulus is 密码 (mi ${ }^{4}$ ma $^{3}$, "password").

\begin{tabular}{|c|c|c|c|c|}
\hline 密码 & 是 & 种 & 保密的 & 手段。 \\
\hline $\mathrm{Mi}^{4} \mathrm{ma}^{3}$ & $\mathrm{shi}^{4}$ & zhong $^{3}$ & $\mathrm{bao}^{3} \mathrm{mi}^{4} \mathrm{de}$ & shou $^{3}$ duan ${ }^{4}$. \\
\hline Password & $\mathrm{BE}$ & Classifier & encrypting & method. \\
\hline Password & & & & \\
\hline
\end{tabular}

Data from Chen and Gussenhoven (2008) and Chen (2010) for Standard Chinese as well as Scholz (2012) and Scholz and Chen (2014) for Wenzhou Chinese show that lexical tones are less influenced by adjacent tonal targets when produced under focus, compared to their post-focus counterparts. (Readers are also referred to Chen, 2012 for further discussions on the effects of on-focus vs. post-focus on tonal realization.) To control the effect of focus, we elicited the utterances as answers to specific questions, resulting in two focus conditions, as illustrated below. In the On-Focus condition, focus was on the target phrase. In the Pre-Focus condition, focus was on later parts of the sentence. In this way, we excluded the possibility that speakers might randomly produce the stimulus sentences with varying information structures. For this particular study, we were not interested in the effect of focus per se and had therefore placed the target stimuli in the sentence-initial subject position, where we knew that the effects of on-focus and pre-focus are closer than in other positions (Xu, 1999).

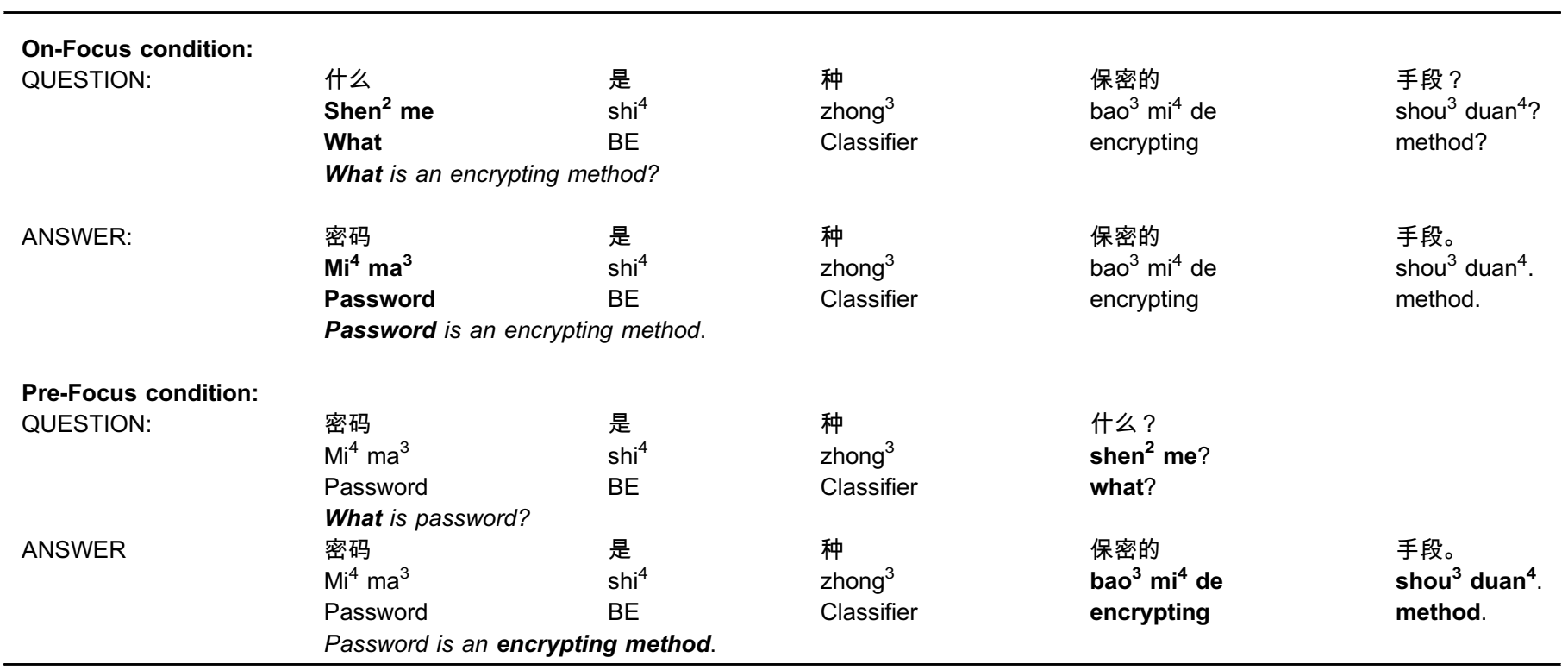

\subsection{Subjects}

Six speakers ( 3 males and 3 females) participated in the experiment. All were local college students, born in the 1980s and raised in the urban areas of Tianjin. None of them had lived outside of Tianjin. They were paid for the participation but unaware of the purpose of the experiment.

\subsection{Recording}

All questions were recorded beforehand in the Phonetics Lab at Leiden University by a native speaker of Tianjin Mandarin. During the experiment, subjects were requested to respond to the question with the targeted response sentence presented on the computer screen. All found the task straightforward and followed the same procedure. Recordings were conducted in a quiet room in Tianjin using an M-Audio ${ }^{\circledR}$ mobile digital audio recorder MicroTrack II with $44.1 \mathrm{kHz}$ sampling rate and 16 bit rate in mono channel.

96 disyllabic items (4 initial tones $* 4$ final tones $* 3$ structures $* 2$ focus conditions) were elicited from each of the six participants, each with two repetitions. 768 trisyllabic items (4 initial tones $* 4$ middle tones $* 4$ final tones $* 3$ structures $* 2$ words $* 2$ focus conditions) were also elicited from each participant. However, one third of the items, with fricative onsets at the second or third syllable, were produced only once. The other two-thirds, with non-fricative onsets, were produced twice. 


\section{4. fO analysis}

The acoustic data were manually segmented in Praat (Boersma \& Weenink, 2011). A custom-written script was used for f0 extraction and smoothing. $f 0$ contours were obtained by taking 20 points (in Hertz) in the rhyme part of each syllable or in the whole syllable for the second syllable within disyllabic constituents where the syllable onsets were all sonorant. To eliminate the pitch range difference due to gender and to better illustrate the tonal variation patterns, each speaker's raw fo data were normalized by converting them to speakerspecific z-scores (Rose, 1987). The plotted tonal contours were then based on the mean z-scores averaged across speakers.

\subsection{Growth curve analysis}

To better understand the varying nature of $f 0$ over the time-course of the tone-bearing syllable, we employed the growth curve analysis (Mirman, 2014) with the package Ime4 (Bates, Maechler, Bolker, \& Walker, 2014) in R (R Core Team, 2014). The growth curve analysis is a multilevel regression technique which is more appropriate and powerful for analyzing non-linear time-varying data (e.g., fo). The advantage of this technique is that the overall $f 0$ contours are taken into consideration. Moreover, the experimental manipulations are better examined by taking into consideration of the random variation due to different subjects.

In growth curve analysis, a non-linear curve is typically fitted with high order orthogonal polynomials, such as, $y=a+b x+c x^{2}+d x^{3}+e x^{4} \ldots$ ( $x$ for time, $y$ for $f 0$ ). The characteristics of a curve could be independently reflected by the coefficients for different time terms in the polynomials. Among them, the intercept $a$ usually indicates the overall mean of a curve; the linear term $b$ indicates the general direction of the curve change (slope); the higher order terms generally reflect the curve complexity (e.g., the quadratic term $c$ for a U-shape curve, cubic $d$ for an S-shape curve, and quartic term e for a W-shape curve).

In this study, we used up to second-order polynomials since the most complex fo contour of one lexical tone in our data has only a convex or concave contour shape. Tonal variation due to different contextual conditions was therefore analyzed by assessing the intercept, linear, and quadratic terms in the fitted model. If two contours differ from each other, we should expect statistical significance in at least one aspect of their $f 0$ contours. This includes the overall $f 0$ mean indexed by the intercept, the direction of $f 0$ change such as rising vs. falling indexed by the slope, and the steepness of fo rising or falling indexed by the quadratic term.

To carry out the growth curve analyses, separate linear mixed-effects models were built for subsets of the data for specific hypothesis testing. For both disyllabic and trisyllabic datasets, we have controlled the tone category, consonant type, vowel height and syllable structure for each syllable within one stimulus. We also controlled the structure (i.e., morpho-syntactic structure for disyllables and grouping structure for trisyllables), focus, repetition and relative familiarity of each stimulus. To determine which controlled factor should be considered in the models, each base model was first established containing only the time terms in the fixed factor structure and the random slope of subject on all time terms. Additional controlled factors were then added in the models in a stepwise fashion. Model fits were tested at each step via model comparisons based on the change in the log-likelihood ratios.
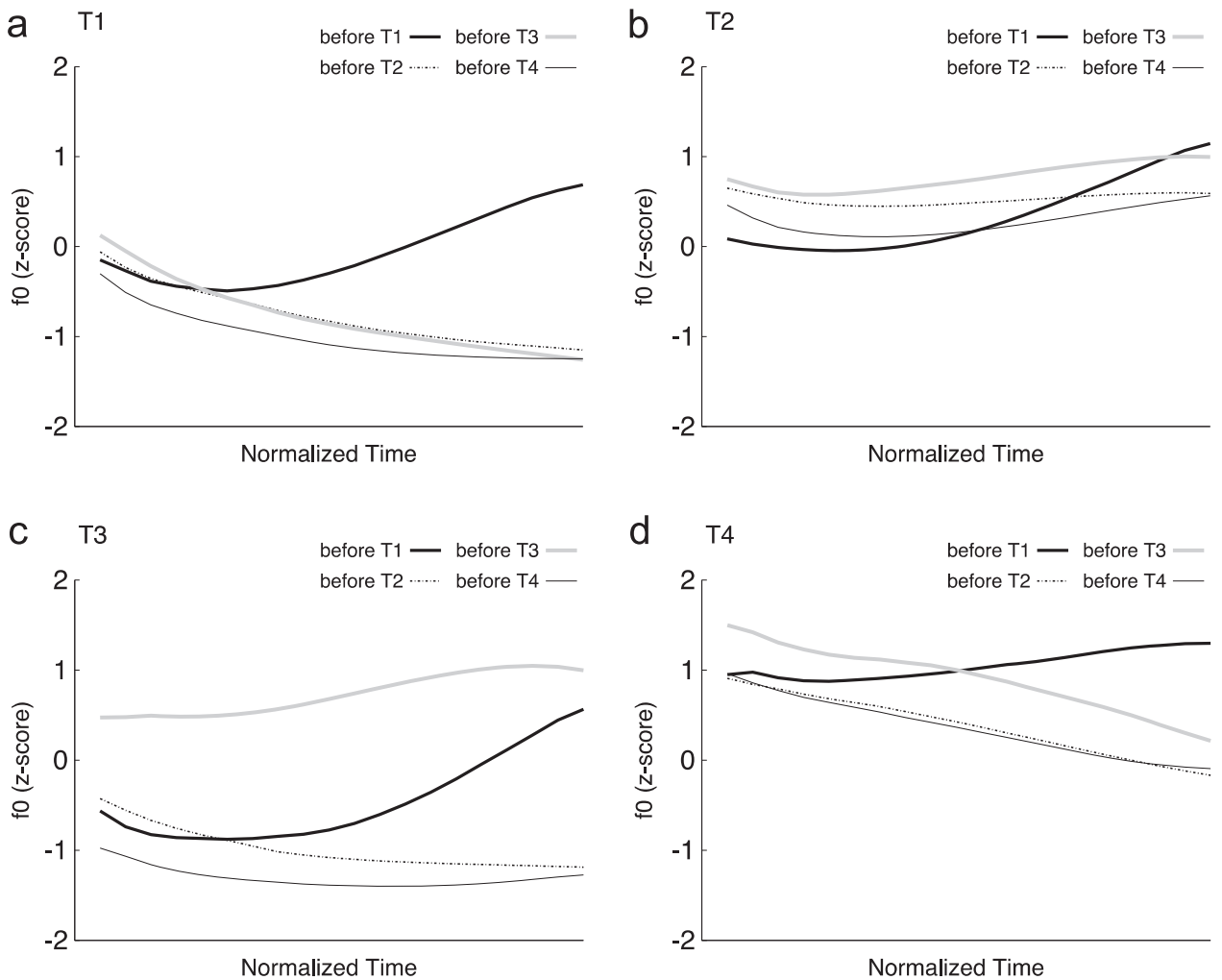

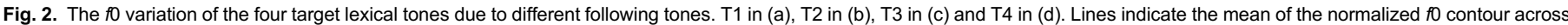
speakers. Normalized time. 
Table 2

Results of pairwise comparison on the variability in the first tone due to different following tones. a for Target T1, b for Target T2, $c$ for Target T3, $d$ for Target T4.

\begin{tabular}{|c|c|c|c|c|c|}
\hline \multicolumn{6}{|c|}{ a. Target T1 } \\
\hline \multicolumn{2}{|c|}{ BeforeT2 vs. beforeT1 } & \multicolumn{2}{|c|}{ BeforeT3 vs. beforeT1 } & \multicolumn{2}{|c|}{ BeforeT4 vs. beforeT1 } \\
\hline Intercept & $\begin{array}{l}\text { Estimate }=-0.67 \\
z=-6.69, p<0.001\end{array}$ & Intercept & $\begin{array}{l}\text { Estimate }=-0.65 \\
z=-5.88, p<0.001\end{array}$ & Intercept & $\begin{array}{l}\text { Estimate }=-0.89 \\
z=-8.86, p<0.001\end{array}$ \\
\hline Slope & $\begin{array}{l}\text { Estimate }=-2.86 \\
z=-11.56, p<0.001\end{array}$ & Slope & $\begin{array}{l}\text { Estimate }=-3.18 \\
z=-12.83, p<0.001\end{array}$ & Slope & $\begin{array}{l}\text { Estimate }=-2.55 \\
z=-10.37, p<0.001\end{array}$ \\
\hline \multirow[t]{9}{*}{ Quadratic } & $\begin{array}{l}\text { Estimate }=-0.43 \\
z=-4.13, p<0.001\end{array}$ & Quadratic & n.s. & Quadratic & $\begin{array}{l}\text { Estimate }=-0.33 \\
z=-3.24, p<0.05\end{array}$ \\
\hline & & \multicolumn{2}{|c|}{ BeforeT3 vs. beforeT2 } & \multicolumn{2}{|c|}{ BeforeT4 vs. beforeT2 } \\
\hline & & Intercept & n.s. & Intercept & n.s. \\
\hline & & Slope & n.s. & Slope & n.s. \\
\hline & & Quadratic & n.s. & Quadratic & n.s. \\
\hline & & & & \multicolumn{2}{|c|}{ BeforeT4 vs. beforeT3 } \\
\hline & & & & Intercept & n.s. \\
\hline & & & & Slope & n.s. \\
\hline & & & & Quadratic & n.s. \\
\hline \multicolumn{6}{|c|}{ b. Target $T 2$} \\
\hline \multicolumn{2}{|c|}{ BeforeT2 vs. beforeT1 } & \multicolumn{2}{|c|}{ BeforeT3 vs. beforeT1 } & \multicolumn{2}{|c|}{ BeforeT4 vs. beforeT1 } \\
\hline Intercept & n.s. & Intercept & n.s. & Intercept & $\begin{array}{l}\text { Estimate }=-0.43 \\
z=-3.77, p<0.01\end{array}$ \\
\hline Slope & $\begin{array}{l}\text { Estimate }=-1.58 \\
z=-8.17, p<0.001\end{array}$ & Slope & $\begin{array}{l}\text { Estimate }=-0.98 \\
z=-5.04, p<0.001\end{array}$ & Slope & $\begin{array}{l}\text { Estimate }=-1.19 \\
z=-6.12, p<0.001\end{array}$ \\
\hline \multirow[t]{9}{*}{ Quadratic } & $\begin{array}{l}\text { Estimate }=-0.45 \\
z=-6.32, p<0.001\end{array}$ & Quadratic & $\begin{array}{l}\text { Estimate }=-0.48 \\
z=-6.42, p<0.001\end{array}$ & Quadratic & $\begin{array}{l}\text { Estimate }=-0.24 \\
z=-3.28, p<0.05\end{array}$ \\
\hline & & \multicolumn{2}{|c|}{ BeforeT3 vs. beforeT2 } & \multicolumn{2}{|c|}{ BeforeT4 vs. beforeT2 } \\
\hline & & Intercept & $\begin{array}{l}\text { Estimate }=0.32 \\
z=3.29, p<0.05\end{array}$ & Intercept & n.s. \\
\hline & & Slope & $\begin{array}{l}\text { Estimate }=0.60 \\
z=3.06, p<0.05\end{array}$ & Slope & n.s. \\
\hline & & Quadratic & n.s. & Quadratic & n.s. \\
\hline & & & & \multicolumn{2}{|c|}{ BeforeT4 vs. beforeT3 } \\
\hline & & & & Intercept & $\begin{array}{l}\text { Estimate }=-0.53 \\
z=-5.38, p<0.001\end{array}$ \\
\hline & & & & Slope & n.s. \\
\hline & & & & Quadratic & $\begin{array}{l}\text { Estimate }=0.24 \\
z=3.22, p<0.05\end{array}$ \\
\hline
\end{tabular}

c. Target $T 3$

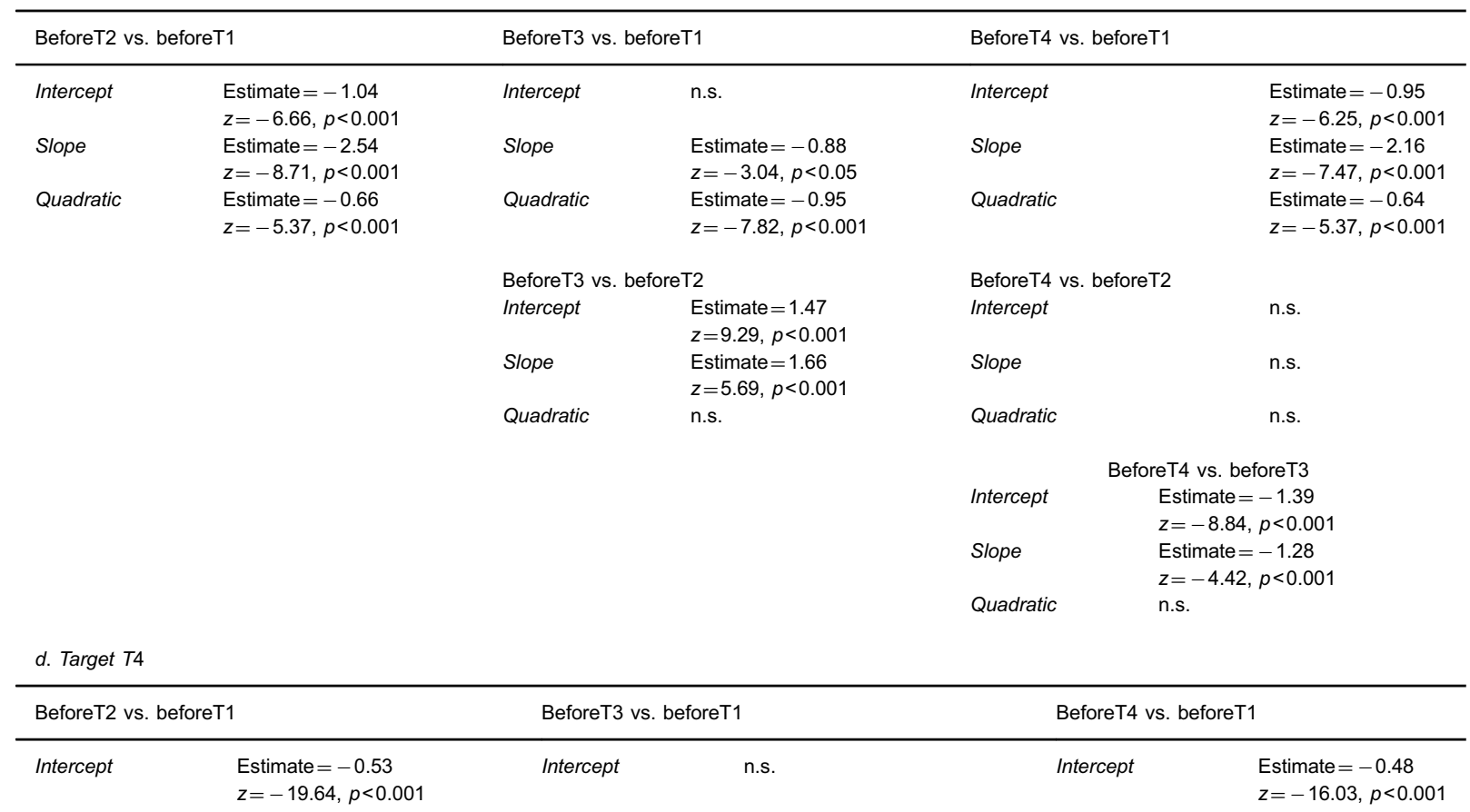




\begin{tabular}{|c|c|c|c|c|c|}
\hline d. Target $T$ & & & & & \\
\hline Slope & $\begin{array}{l}\text { Estimate }=-2.02 \\
z=-21.61, p<0.001\end{array}$ & Slope & $\begin{array}{l}\text { Estimate }=-2.18 \\
z=-23.99, p<0.001\end{array}$ & Slope & $\begin{array}{l}\text { Estimate }=-2.03 \\
z=-22.25, p<0.001\end{array}$ \\
\hline \multirow[t]{9}{*}{ Quadratic } & n.s. & Quadratic & $\begin{array}{l}\text { Estimate }=-0.40 \\
z=-4.31, p<0.001\end{array}$ & Quadratic & n.s. \\
\hline & & \multicolumn{2}{|c|}{ BeforeT3 vs. beforeT2 } & \multicolumn{2}{|c|}{ BeforeT4 vs. beforeT2 } \\
\hline & & Intercept & $\begin{array}{l}\text { Estimate }=0.52 \\
z=19.84, p<0.001\end{array}$ & Intercept & n.s. \\
\hline & & Slope & n.s. & Slope & n.s. \\
\hline & & Quadratic & n.s. & Quadratic & n.s. \\
\hline & & & & \multicolumn{2}{|c|}{ BeforeT4 vs. beforeT3 } \\
\hline & & & & Intercept & $\begin{array}{l}\text { Estimate }=-0.46 \\
z=-18.07, p<0.001\end{array}$ \\
\hline & & & & Slope & n.s. \\
\hline & & & & Quadratic & n.s. \\
\hline
\end{tabular}

Controlled factors that significantly improved the model fits were kept in the fixed factor structure of the models. Parameter-specific $p$ values were estimated using the normal approximation (i.e., treating the $t$-value as a $z$-value). Multiple comparisons with Bonferroni adjustment were conducted with the function glht in package multcomp (Hothorn, Bretz, \& Westfall, 2008) whenever necessary.

\section{Results and discussion I: tonal variation in disyllabic domain}

\subsection{Results}

We were interested in the potential differences in tonal variation due to coarticulation and tone sandhi. Given that tone sandhi of disyllabic sequences in Tianjin Mandarin involves the modification of the first tone as a function of its following tone, we zoomed into the $f 0$ contours of each first tone followed by different second tones (i.e., the anticipatory effects), as plotted in Fig. 2. For our planned comparisons, the whole disyllabic dataset was separated into four subsets according to the tonal category of the first tone. The statistical results were summarized in Table 2.

\subsection{1. $T 1 T x$}

As shown in Fig. 2a, the first T1 remains as a low-falling tone except when it is followed by another T1, in which case, it surfaces with a rising $f 0$ contour. This difference was statistically significant, as supported by results in Table $2 \mathrm{a}$, where the $f 0$ contour of $\mathrm{T} 1$ before another T1 showed a significant difference from that before the other tones. (See significant statistical results of target T1 beforeT2 vs. beforeT1, beforeT3 vs. beforeT1, and beforeT4 vs. beforeT1.) For T1 before T2, T3, and T4, however, we did not see any significant difference. (See the lack of significant results of target T1 beforeT3 vs. beforeT2, beforeT4 vs. beforeT2, and beforeT4 vs. beforeT3.)

\subsection{2. $T 2 T x$}

Fig. $2 \mathrm{~b}$ shows that, the first T2 remains a high-rising tone regardless of the identity of the following tone. There are, however, some subtle differences restricted to two contexts, i.e., before T1 and T3.

Before T1, there was a slight yet consistent fo rise towards the end of the tone-bearing syllable compared to that before the other three tones, confirmed by the significant statistical results in the slope and quadratic components in Table $2 \mathrm{~b}$. (See target $\mathrm{T} 2$ beforeT2 vs. beforeT1, beforeT3 vs. beforeT1, beforeT4 vs. beforeT1.) The raising effect before T1 on T2 was somehow different from the raising effect of T3 on T2. When followed by a T3, there was an overall raising effect of the whole f0 mean contour, which was supported by the significant results in the intercept. (See target T2 beforeT3 vs. beforeT2 and beforeT4 vs. beforeT3.) In addition, there were some slight and less consistent contour differences when T2 was followed by T3, compared to that followed by T2 and T4 (reflected in the significant results of slope in target T2 beforeT3 vs. beforeT2 and quadratic component in target T2 beforeT4 vs. beforeT3). There was no significant difference in the f0 contours of T2 beforeT2 vs. beforeT4.

\subsection{3. $T 3 T x$}

Fig. $2 \mathrm{c}$ shows that the target T3 varies greatly as a function of the following tones, which again were restricted mainly to two contexts, i.e., before T1 and T3. Before T1, there was a consistently greater f0 rise compared to that before the other three tones, as confirmed by the significant results in the slope and quadratic components in Table 2c. (See target T3 beforeT2 vs. beforeT1, beforeT3 vs. beforeT1, beforeT4 vs. beforeT1.) This is different from the general T3 raising effect before another T3, which was 
mainly confirmed by the significant intercept differences. (See target T3 beforeT3 vs. beforeT2 and beforeT4 vs. beforeT3.) This T3 raising effect is similar to what we have observed for the raising effect of T3 on the preceding target T2, but with a much greater magnitude. In addition, probably due to the slightly falling fo before T2 and T4, we also observed a significant difference in the slope. (See again target T3 beforeT3 vs. beforeT2, beforeT4 vs. beforeT3.)

\subsection{4. $T 4 T x$}

Fig. $2 \mathrm{~d}$ shows that the variation of T4 was also restricted to the two following tonal contexts, i.e., T1 and T3, as observed for targets T2 and T3 earlier. T1 again, introduced a significantly greater fo rise on its preceding T4 in terms of significant slope differences shown in Table 2d, in addition to the less consistent intercept and quadratic differences. (See target T4 beforeT2 vs. beforeT1, beforeT3 vs. beforeT1, beforeT4 vs. beforeT1.) Before T3, T4 showed a more general overall f0 raising effect, as indicated by the significantly different intercepts. (See target T4 beforeT3 vs. beforeT2 and beforeT4 vs. beforeT3.) There was no significant difference in the fo contours of T4 before T2 vs. T4.

\subsection{Discussion}

Within disyllabic tonal sequences, we have observed a range of variation in the fo realization of four lexical tones due to different following tones. The results were summarized in Table 3, where within a disyllabic tonal sequence, the first tone was affected in terms of both the overall $f 0$ mean as well as the fo contour shape.

With regard to the overall f0 mean, all tones (except T1) were significantly raised by the following T3 compared to those preceding other tones. It is important to note that the raising over T3 was significantly greater than that over T2 and T4. In terms of f0 contour change, what we observed was the consistent $f 0$ rise over all lexical tones that preceded T1. Their magnitudes of $f 0$ rise were fairly comparable regardless of the identity of the target tones.

As introduced earlier, there is consensus in the literature that T1T1, T4T1, and T3T3 undergo tone sandhi changes (e.g., Li \& Liu, 1985; Hung, 1987; Tan, 1987; Zhang, 1987; Chen, 2000; J. Wang, 2002; Hyman, 2007). T4T3 has been reported to involve anticipatory tonal coarticulation (Zhang \& Liu, 2011). Furthermore, it has been proposed in the literature that T3T2, T3T4 and T4T4 also involve tone sandhi (see Wee et al., 2005; Zhang \& Liu, 2011 for T3T2 and T3T4 sandhi; see Li \& Liu, 1985; Hung, 1987; Tan, 1987; Zhang, 1987; Chen, 2000; J. Wang, 2002; Hyman, 2007 for T4T4 sandhi). Our results showed that there was no significant tonal alternation in T3T2, T3T4, and T4T4, raising questions to the application of tone sandhi over these sequences. Instead, we observed a clear fo contour raising effect of T1 on T2 and T3 (Fig. $2 b$ and c) as well as a general raising effect of T3 on T2 (Fig. 2 b), which have never been reported in the literature either as a tone sandhi change or as contextual tonal coarticulation.

Traditionally, tone sandhi in Tianjin Mandarin has always been characterized as the categorical change of one lexical tone to another within the lexical tone inventory (e.g., Li \& Liu, 1985; Hung, 1987; Tan, 1987; Zhang, 1987; Chen, 2000; J. Wang, 2002; Hyman, 2007). With the three tonal sequences that have been claimed to undergo tone sandhi (i.e., T1T1, T4T1, T3T3), which did show contextual tonal variation in our data, we further examined whether they involved categorical sandhi changes into T2/T3T1, T2T1 and T2T3, respectively. Our approach was to compare the $f 0$ contours of the three sandhi sequences to the $f 0$ realization of their respective targeted outputs claimed in the literature (i.e., T1T1 vs. T2/T3T1, T4T1 vs. T2T1 and T3T3 vs. T2T3).

Plotted in Fig. 3 are the $f 0$ contours of the three sandhi sequences (in dark gray) against the fo contours of their respective claimed targeted outputs (in light gray). Specifically, T1T1 (against T2/T3T1) is shown in Fig. 3a, T4T1 (against T2T1) in Fig. 3b, and T3T3 (against T2T3) in Fig. 3c. Statistical results of their planned comparisons are summarized in Table 4.

Fig. 3 shows that all the three tonal sequences were produced significantly differently from their claimed targeted outputs, as confirmed by significant statistical results in Table 4. Our results thus confirmed the non-neutralization in the three disyllabic tonal sequences as found in Zhang and Liu (2011). Apparently, tonal neutralization cannot be the criterion of what constitutes tone sandhi. The question is then what differentiates tone sandhi from phonetic tonal coarticulation?

Table 3

Summary of variability in the first tone due to different following tones.

\begin{tabular}{|c|c|c|c|c|}
\hline \multirow[t]{2}{*}{ 1st Tone } & \multicolumn{4}{|l|}{ 2nd Tone } \\
\hline & $\begin{array}{l}\text { T1 (low- } \\
\text { falling) }\end{array}$ & $\begin{array}{l}\text { T2 (high- } \\
\text { rising) }\end{array}$ & T3 (low-dipping) & $\begin{array}{l}\text { T4 (high- } \\
\text { falling) }\end{array}$ \\
\hline $\begin{array}{l}\text { T1 (low- } \\
\text { falling) }\end{array}$ & $\begin{array}{l}\text { Greater fo } \\
\text { rise }\end{array}$ & No effect & No effect & No effect \\
\hline $\begin{array}{l}\text { T2 (high- } \\
\text { rising) }\end{array}$ & $\begin{array}{l}\text { Greater fo } \\
\text { rise }\end{array}$ & No effect & $\begin{array}{l}\text { Slightly raised } \\
\text { overall fo contour }\end{array}$ & No effect \\
\hline $\begin{array}{l}\text { T3 (low- } \\
\text { dipping) }\end{array}$ & $\begin{array}{l}\text { Greater fo } \\
\text { rise }\end{array}$ & No effect & $\begin{array}{l}\text { Greatly raised } \\
\text { overall } f 0 \text { contour; } \\
\text { Small } f 0 \text { rise }\end{array}$ & No effect \\
\hline $\begin{array}{l}\text { T4 (high- } \\
\text { falling) }\end{array}$ & $\begin{array}{l}\text { Greater fo } \\
\text { Rise }\end{array}$ & No effect & $\begin{array}{l}\text { Slightly raised } \\
\text { overall fo contour }\end{array}$ & No effect \\
\hline
\end{tabular}



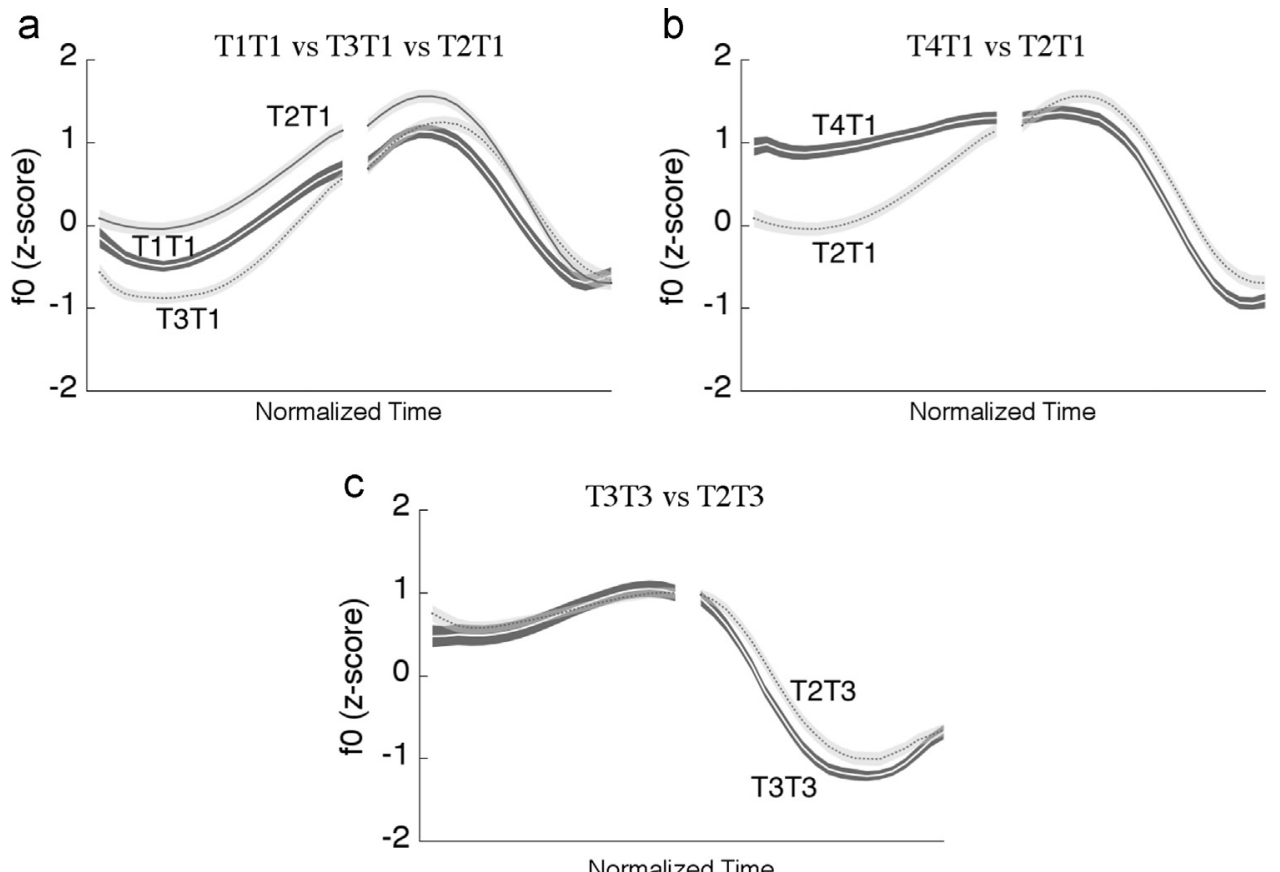

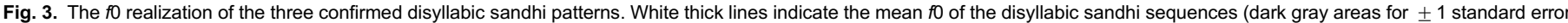
of mean); black lines indicate the mean $f 0$ of the claimed targeted output (light gray areas for \pm 1 standard error of mean). Normalized time.

Table 4

Results of growth curve analyses for T1T1 vs. T2T1/T3T1, T4T1 vs. T2T1, T3T3 vs. T2T3. Bolded items for tones under comparison.

\begin{tabular}{|c|c|c|c|c|}
\hline & \multicolumn{2}{|l|}{ T1T1 } & \multirow{2}{*}{$\begin{array}{l}\text { T4T1 } \\
\text { T4T1 vs. T2T1 }\end{array}$} & \multirow{2}{*}{$\begin{array}{l}\text { T3Т3 } \\
\text { T3T3 vs. T2T3 }\end{array}$} \\
\hline & T3T1 vs. T1T1 & T2T1 vs. T1T1 & & \\
\hline Intercept & $\begin{array}{l}\text { Estimate }=-0.41 \\
t=-12.87, p<0.001\end{array}$ & $\begin{array}{l}\text { Estimate }=0.22 \\
t=8.69, p<0.001\end{array}$ & $\begin{array}{l}\text { Estimate }=0.71 \\
t=19.52, p<0.001\end{array}$ & n.s. \\
\hline Slope & n.s. & n.s. & $\begin{array}{l}\text { Estimate }=-1.02 \\
t=-11.42, p<0.001\end{array}$ & $\begin{array}{l}\text { Estimate }=0.25 \\
t=2.81, p<0.01\end{array}$ \\
\hline Quadratic & $\begin{array}{l}\text { Estimate }=0.27 \\
t=2.66, p<0.01\end{array}$ & n.s. & $\begin{array}{l}\text { Estimate }=-0.48 \\
t=-5.37, p<0.001\end{array}$ & n.s. \\
\hline
\end{tabular}

Generally speaking, phonetic coarticulation caused by the following tone should not affect the distinctiveness of a lexical tonal contour (e.g., Gandour et al., 1994; Xu, 1997), so that its characteristic f0 contour can still be expected to accord with its canonical tonal shape. A phonological tone sandhi alternation, however, usually brings about major changes in the fo contour of a lexical tone so that its surface $f 0$ may be unpredictable from the characteristics of the canonical tonal fo contour. Among the seven disyllabic cases that exhibited a statistically significant amount of tonal variance as shown in Table 3, both falling tones T1 and T4 were realized with rising $f 0$ contours due to the contour raising effect triggered by the following T1 (i.e., in T1T1 and T4T1); the low-dipping T3 was realized with a high $f 0$ register due to the general raising effect from the following T3 (i.e., in T3T3). These altered f0 realizations were unpredictable from its canonical low tones, and therefore seemed justified to be categorized as tone sandhi. In the other four cases, i.e., T3T1, T2T1, T2T3, T4T3, however, the fo realization of the first tone was rather recognizable despite variation due to the following tone. It is not clear therefore whether a sandhi rule is necessary for these four cases.

To summarize, we have confirmed three disyllabic tonal sequences to be tone sandhi patterns as reported in the literature, i.e., T1T1, T4T1 and T3T3 (e.g., Li \& Liu, 1985; Hung, 1987; Tan, 1987; Zhang, 1987; Chen, 2000; J. Wang, 2002; Ma, 2005; Hyman, 2007). We also found a significant anticipatory raising effect, though with minor modifications, on T2 and T4 before T3, as well as a significant contour raising effect on T2 and T3 before T1. All other tonal sequences were found to induce non-significant (probably perceptually negligible) phonetic changes.

Note that even for the confirmed tone sandhi cases, it is clear that sandhi does not involve categorical change of one lexical tone to another. The lack of tonal neutralization makes it clear that tone sandhi in Tianjin Mandarin should not be characterized as the categorical change of one lexical tone to another. Such a lack of categorical sandhi change also raises serious doubts on the tonal variation patterns of trisyllabic constituents reported in the literature. 


\section{Results and discussion II: tonal variation in trisyllabic domain}

In this section, we examined tonal variation in Tianjin Mandarin over trisyllabic domains. We limited our attention to the three disyllabic sandhi processes confirmed so far and investigated how these sandhi changes are applied in trisyllabic sequences. Each trisyllabic sequence was compared to the targeted output pattern as claimed in the literature. Table 5 concludes all the sandhiinvolved trisyllabic combinations discussed in the literature based on the three disyllabic processes. (Some combinations might appear twice in this table due to the fact that some disyllabic patterns are involved in more than one trisyllabic combinations.) We separated our analyses according to the classification of simple vs. complex tone sandhi contexts proposed in the literature. In the simple sandhi contexts, the directionality of sandhi application was investigated whereas in the complex sandhi contexts (bolded), we aimed to tap into the iterativity of sandhi application in addition to the directionality.

Table 5

All trisyllabic tone sandhi combinations proposed in the literature involving T1T1, T4T1 and T3T3. The bold items are those possibly involving complex tonal contexts.

\begin{tabular}{|c|c|c|c|c|c|c|}
\hline & \multicolumn{2}{|l|}{$\mathrm{T} 1 \mathrm{~T} 1$} & \multicolumn{2}{|l|}{ T4T1 } & \multicolumn{2}{|l|}{ Т3Т3 } \\
\hline & Left-aligned & Right-aligned & Left-aligned & Right-aligned & Left-aligned & Right-aligned \\
\hline T1 & \multicolumn{2}{|c|}{ T1T1T1 } & T4T1T1 & T1T4T1 & ТЗТЗТ1 & Т1Т3Т3 \\
\hline T2 & T1T1T2 & T2T1T1 & T4T1T2 & $\mathrm{T} 2 \mathrm{~T} 4 \mathrm{~T} 1$ & ТЗТЗТ2 & Т2Т3Т3 \\
\hline T3 & T1T1T3 & T3T1T1 & T4T1T3 & Т3Т4T1 & \multicolumn{2}{|c|}{ Т3Т3Т3 } \\
\hline T4 & T1T1T4 & T4T1T1 & T4T1T4 & T4T4T1 & ТЗТ3Т4 & Т4Т3Т3 \\
\hline
\end{tabular}

T1T1Tx

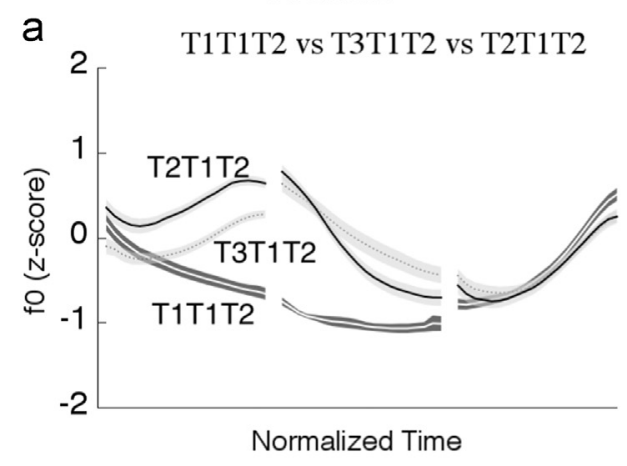

b 2 T1T1T3 vs T3T1T3 vs T2T1T3
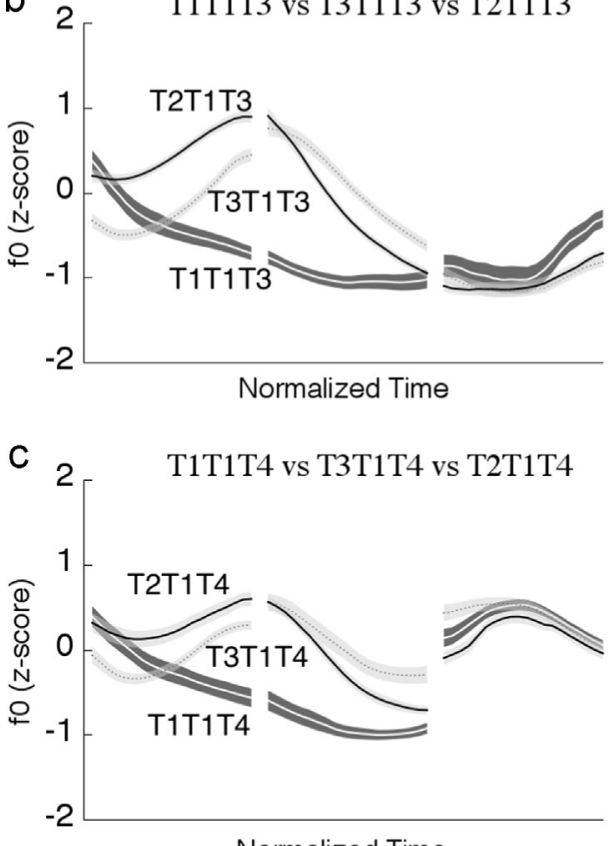

TxT1T1

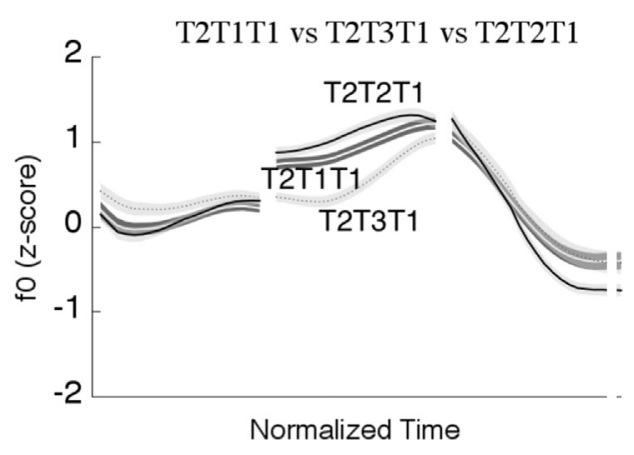

Normalized Time

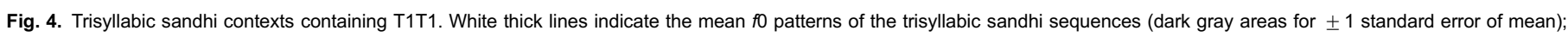

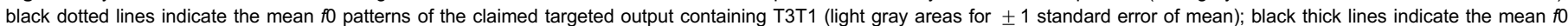
patterns of the claimed targeted output containing T2T1 (light gray areas for \pm 1 standard error of mean). Normalized time. 


\subsection{Simple sandhi contexts}

We set up the simple sandhi contexts as aligning a disyllabic sandhi tonal sequence either to the left or right of a trisyllabic constituent, without involving potentially multiple applications of tone sandhi. In Figs. 4-6, the f0 contours of the trisyllabic sequences (in dark gray) were compared to the fo realization of their respective sandhi targeted outputs as claimed in the literature (in light gray). Note that those plotted on the left have the sandhi contexts in the first two syllables (left-aligned); and those on the right have the sandhi contexts in the last two syllables (right-aligned). Merged $f 0$ contours are expected if there is neutralization in tone sandhi. Again, for the case of T1T1, both T2T1 and T3T1 were included given that both possibilities have been proposed in the literature. The statistical results are summarized in Tables 6-8.

\section{TxT4T1}

T1T4T1 vs T1T2T1

a

T4T1Tx
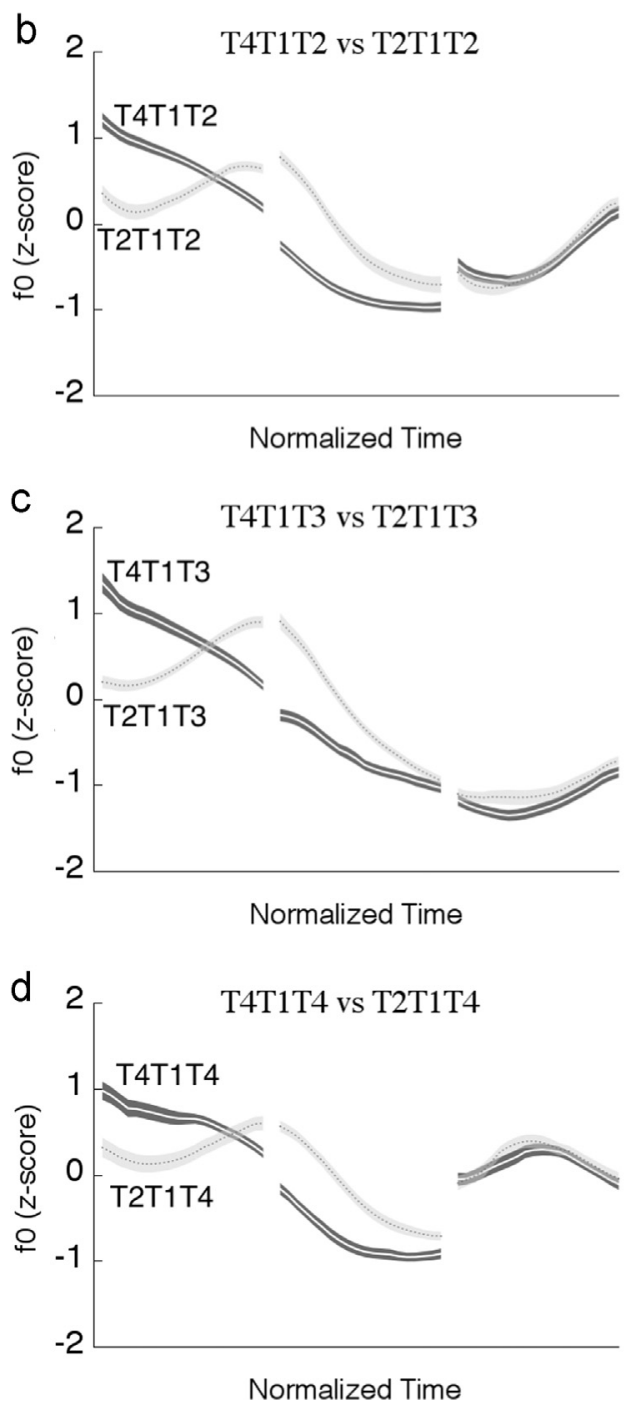
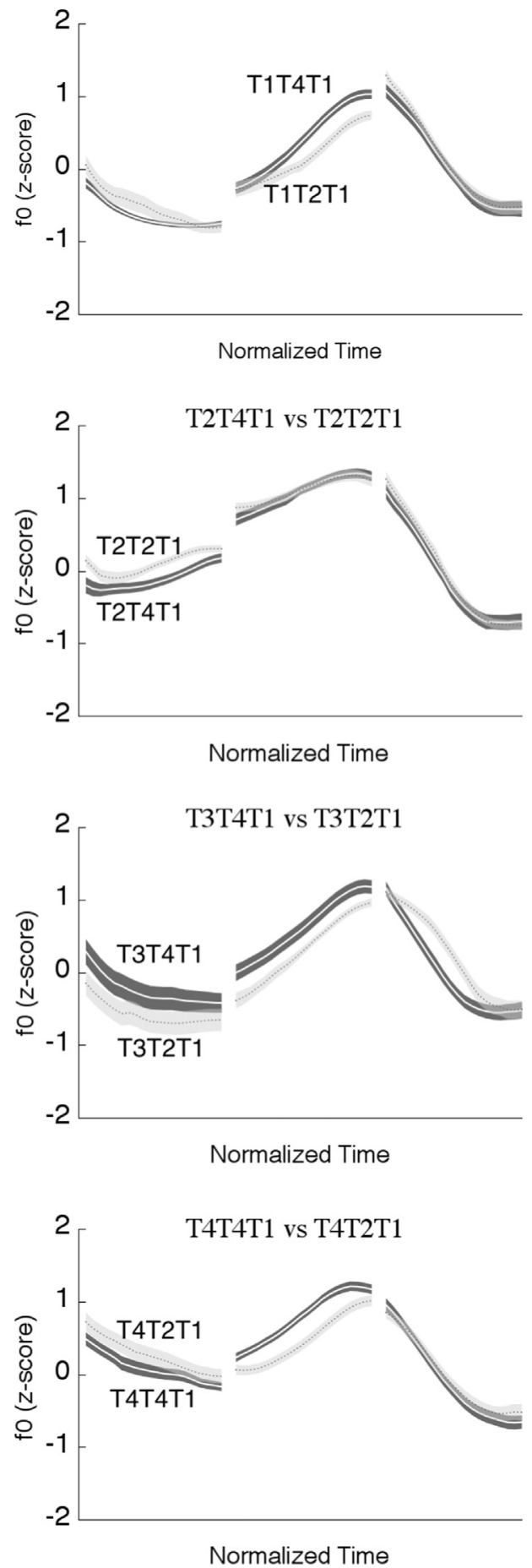

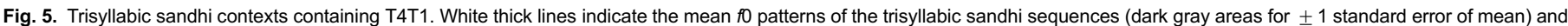
black dotted lines indicate the mean $f 0$ patterns of the claimed targeted outputs (light gray areas for \pm 1 standard error of mean). Normalized time. 
T3T3Tx
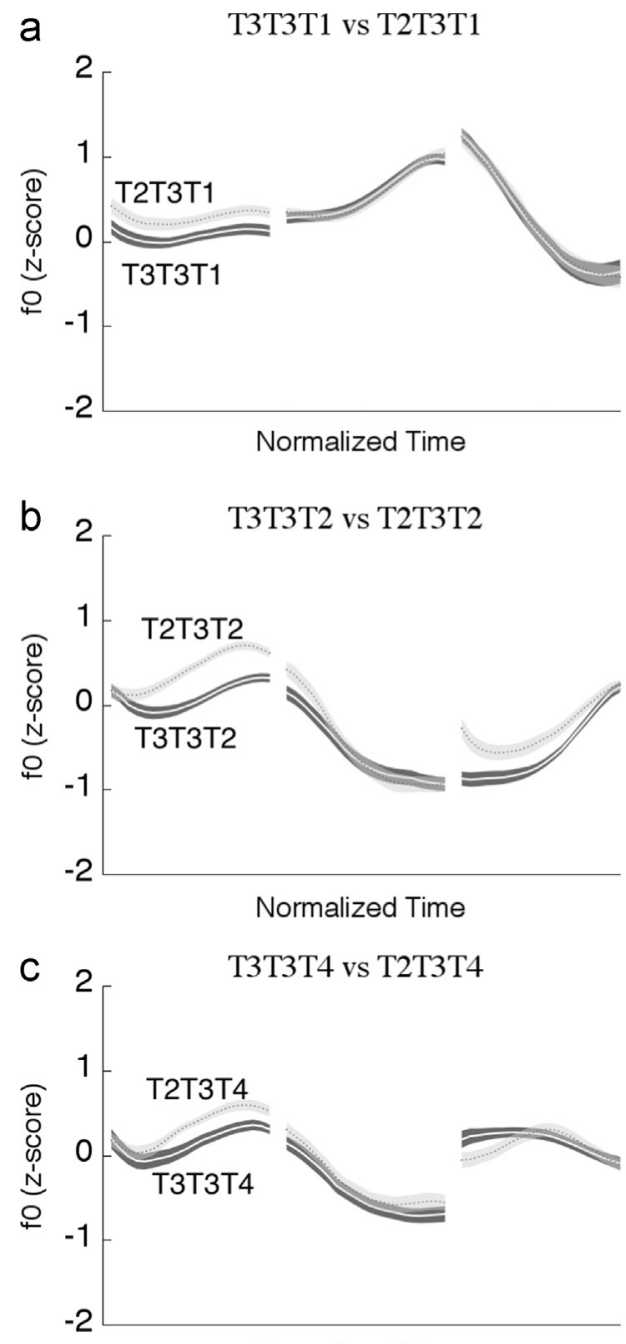

Normalized Time
TxT3T3

T1T3T3 vs T1T2T3
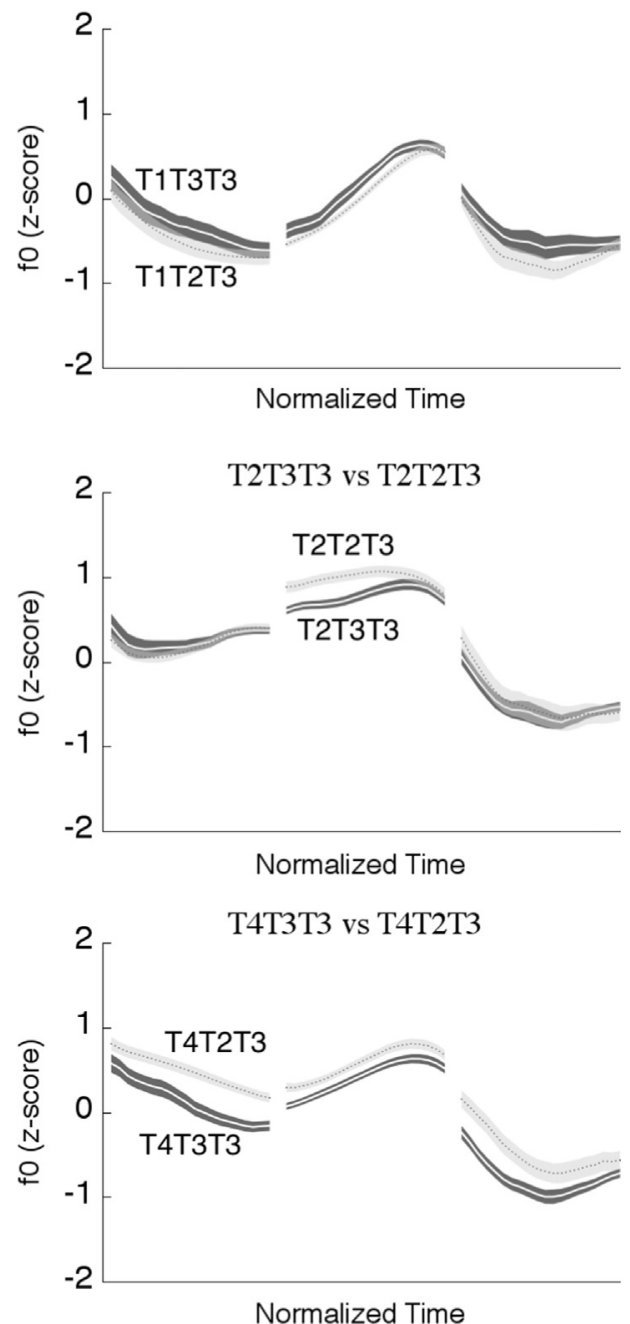

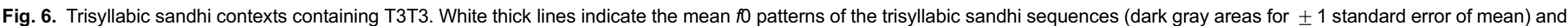
black dotted lines indicate the mean $f 0$ patterns of the claimed targeted outputs (light gray areas for \pm 1 standard error of mean). Normalized time.

Table 6

Results of growth curve analyses for T1T1Tx vs. TxT1T1. Bolded items for tones under comparison.

\begin{tabular}{|c|c|c|c|c|}
\hline & \multicolumn{2}{|l|}{ T1T1Tx } & \multicolumn{2}{|l|}{ TxT1T1 } \\
\hline & T1T1T2 vs. T2T1T2 & T1T1T2 vs. T3T1T2 & T2T1T1 vs. T2T2T1 & T2T1T1 vs. Т2Т3T1 \\
\hline Intercept & $\begin{array}{l}\text { Estimate }=0.93 \\
t=38.35, p<0.001\end{array}$ & $\begin{array}{l}\text { Estimate }=0.56 \\
t=18.91, p<0.001\end{array}$ & n.s. & $\begin{array}{l}\text { Estimate }=-0.28 \\
t=-13.05, p<0.001\end{array}$ \\
\hline Slope & $\begin{array}{l}\text { Estimate }=1.78 \\
t=19.69, p<0.001\end{array}$ & $\begin{array}{l}\text { Estimate }=1.73 \\
t=19.06, p<0.001\end{array}$ & n.s. & $\begin{array}{l}\text { Estimate }=0.36 \\
t=4.09, p<0.001\end{array}$ \\
\hline Quadratic & n.s. & n.s. & $\begin{array}{l}\text { Estimate }=-0.21 \\
t=-2.36, p<0.05\end{array}$ & $\begin{array}{l}\text { Estimate }=0.29 \\
t=3.26, p<0.01\end{array}$ \\
\hline & T1T1T3 vs. T2T1T3 & T1T1T3 vs. T3T1T3 & & \\
\hline Intercept & $\begin{array}{l}\text { Estimate }=1.05 \\
t=21.10, p<0.001\end{array}$ & $\begin{array}{l}\text { Estimate }=0.47 \\
t=10.87, p<0.001\end{array}$ & & \\
\hline Slope & $\begin{array}{l}\text { Estimate }=2.48 \\
t=21.15, p<0.001\end{array}$ & $\begin{array}{l}\text { Estimate }=2.63 \\
t=22.46, p<0.001\end{array}$ & & \\
\hline Quadratic & n.s. & n.s. & & \\
\hline & T1T1T4 vs. T2T1T4 & T1T1T4 vs. T3T1T4 & & \\
\hline Intercept & $\begin{array}{l}\text { Estimate }=0.91 \\
t=26.35, p<0.001\end{array}$ & $\begin{array}{l}\text { Estimate }=0.50 \\
t=11.53, p<0.001\end{array}$ & & \\
\hline Slope & $\begin{array}{l}\text { Estimate }=1.77 \\
t=14.67, p<0.001\end{array}$ & $\begin{array}{l}\text { Estimate }=2.04 \\
t=16.82, p<0.001\end{array}$ & & \\
\hline Quadratic & n.s. & n.s. & & \\
\hline
\end{tabular}




\subsubsection{T1T1Tx vs. TxT1T1}

As shown in Fig. 4, the application of T1T1 sandhi can only be observed when T1T1 is right aligned. However, the sandhi-T1 was not neutralized with either T3 or T2. The non-neutralization pattern confirms what we have observed in disyllabic T1T1 tonal sequences. Specifically, when T1T1 was left aligned (i.e., T1T1T2, T1T1T3, T1T1T4 in Fig. 4a-c, left column), the first T1 was clearly realized with a falling $f 0$ contour, which was the opposite of that of T2/T3, as confirmed by the significant differences in the slope (see

Table 7

Results of growth curve analyses for T4T1Tx vs. TxT4T1. Bolded items for tones under comparison.

\begin{tabular}{|c|c|c|}
\hline & T4T1Tx & TxT4T1 \\
\hline & & T1T4T1 vs. T1T2T1 \\
\hline Intercept & & $\begin{array}{l}\text { Estimate }=0.25, t=7.71, \\
p<0.001\end{array}$ \\
\hline Slope & & $\begin{array}{l}\text { Estimate }=0.48, t=4.83 \\
p<0.001\end{array}$ \\
\hline \multirow[t]{2}{*}{ Quadratic } & & $\begin{array}{l}\text { Estimate }=-0.25, t=-2.49, \\
p<0.05\end{array}$ \\
\hline & T4T1T2 vs. T2T1T2 & T2T4T1 vs. T2T2T1 \\
\hline Intercept & $\begin{array}{l}\text { Estimate }=0.17, t=4.40, \\
p<0.001\end{array}$ & $\begin{array}{l}\text { Estimate }=0.05, t=2.42, \\
p<0.05\end{array}$ \\
\hline Slope & $\begin{array}{l}\text { Estimate }=-2.05 \\
t=-24.07, p<0.001\end{array}$ & $\begin{array}{l}\text { Estimate }=0.25, t=2.89, \\
p<0.01\end{array}$ \\
\hline \multirow[t]{2}{*}{ Quadratic } & $\begin{array}{l}\text { Estimate }=-0.31, t=-3.68 \\
p<0.001\end{array}$ & n.s. \\
\hline & T4T1T3 vs. T2T1T3 & T3T4T1 vs. ТЗТ2T1 \\
\hline Intercept & n.s. & $\begin{array}{l}\text { Estimate }=0.30, t=3.48 \\
p<0.01\end{array}$ \\
\hline Slope & $\begin{array}{l}\text { Estimate }=-3.00 \\
t=-32.89, p<0.001\end{array}$ & n.s. \\
\hline \multirow[t]{2}{*}{ Quadratic } & $\begin{array}{l}\text { Estimate }=-0.33, t=-3.71 \\
p<0.001\end{array}$ & n.s. \\
\hline & T4T1T4 vs. T2T1T4 & T4T4T1 vs. T4T2T1 \\
\hline Intercept & $\begin{array}{l}\text { Estimate }=0.71, t=17.13 \\
p<0.001\end{array}$ & n.s. \\
\hline Slope & $\begin{array}{l}\text { Estimate }=-1.41 \\
t=-12.88, p<0.001\end{array}$ & n.s. \\
\hline Quadratic & $\begin{array}{l}\text { Estimate }=-0.41, t=-3.77 \\
p<0.001\end{array}$ & $\begin{array}{l}\text { Estimate }=-0.36, t=-4.25, \\
p<0.001\end{array}$ \\
\hline
\end{tabular}

Table 8

Results of growth curve analyses for ТЗТЗTx vs. ТхТЗТ3. Bolded items for tones under comparison.

\begin{tabular}{|c|c|c|}
\hline & ТЗТ3Тx & ТхТ3Т3 \\
\hline & T3Т3T1 vs. Т2Т3Т1 & T1T3T3 vs. T1T2T3 \\
\hline Intercept & n.s. & $\begin{array}{l}\text { Estimate }=-0.55 \\
t=-11.47, p<0.001\end{array}$ \\
\hline Slope & n.s. & n.s. \\
\hline \multirow[t]{2}{*}{ Quadratic } & n.s & $\begin{array}{l}\text { Estimate }=-0.19, t=-2.45 \\
p<0.05\end{array}$ \\
\hline & T3Т3T2 vs. T2T3T2 & T2T3T3 vs. T2T2T3 \\
\hline Intercept & $\begin{array}{l}\text { Estimate }=-0.09 \\
t=-2.87, p<0.01\end{array}$ & $\begin{array}{l}\text { Estimate }=-0.07, t=-2.03, \\
p<0.05\end{array}$ \\
\hline Slope & $\begin{array}{l}\text { Estimate }=-0.45 \\
t=-5.98, p<0.001\end{array}$ & $\begin{array}{l}\text { Estimate }=0.33, t=4.54 \\
p<0.001\end{array}$ \\
\hline \multirow[t]{2}{*}{ Quadratic } & $\begin{array}{l}\text { Estimate }=0.42, t=5.54, \\
p<0.001\end{array}$ & n.s. \\
\hline & T3T3T4 vs. T2T3T4 & T4T3T3 vs. T4T2T3 \\
\hline Intercept & $\begin{array}{l}\text { Estimate }=-0.29 \\
t=-8.45, p<0.001\end{array}$ & $\begin{array}{l}\text { Estimate }=-0.14, t=-7.35, \\
p<0.001\end{array}$ \\
\hline Slope & $\begin{array}{l}\text { Estimate }=-0.33 \\
t=-3.57, p<0.001\end{array}$ & n.s. \\
\hline Quadratic & $\begin{array}{l}\text { Estimate }=0.23, t=2.50, \\
p<0.05\end{array}$ & n.s. \\
\hline
\end{tabular}


T1T1Tx in Table 6). When T1T1 was right aligned as in T2T1T1 (Fig. 4a, right), the middle T1 was realized with a rising f0 contour, suggesting the application of tone sandhi (Fig. 3a). However, the significant statistical results suggested no tonal neutralization between the middle T1 vs. its claimed output T2 or T3 (see T1T1Tx in Table 6).

\subsubsection{T4T1TX vs. TXT4T1}

As shown in Fig. 5, T4T1 also undergoes tone sandhi only when it is right aligned, as observed earlier for T1T1. Again, no tonal neutralization was confirmed between T4 and its claimed output T2. Specifically, when T4T1 was left aligned (i.e., T4T1T2, T4T1T3, T4T1T4 in Fig. 5a-c, left column), tone sandhi could not have applied, given its falling fo contour. This was confirmed by the significant slope difference between T2 and T4 in all the left-aligned cases (T4T1Tx in Table 7). When T4T1 was right aligned (i.e., T1T4T1, T2T4T1, T3T4T1, T4T4T1 in Fig. 5a-d, right), the rising f0 contour over the T4-bearing syllable suggested the application of tone sandhi (as comparable to that in disyllabic sequences shown in Fig. 3b), but again no neutralization was confirmed. See significant statistical results of the f0 differences between TxT4T1 vs. TxT2T1, summarized in Table 7.

\subsubsection{T3T3Tx vs. TXT3T3}

Fig. 6 displays the T3T3 sequence in the left-aligned contexts (T3T3T1, T3T3T2, T3T3T4 in Fig. 6a-c, left) and the right-aligned contexts (T1T3T3, T2T3T3, T4T3T3 in Fig. 6a-c, right). Note that T3T3T3 will be discussed in Section 4.2 .1 due to its potentially complex tone sandhi application. In both T3T3Tx and TxT3T3, the first T3 showed a rising f0 contour, suggesting the consistent application of the T3 sandhi, as observed in disyllabic T3T3 sequence (Fig. 3c). However, sandhi-T3 showed significant differences from T2 in all the other tonal contexts (see significant results in both T3T3Tx and TxT3T3 in Table 8), except for the sequence T3T3T1. This confirmed again the general lack of complete neutralization in these tone sandhi cases.

\subsection{Complex sandhi contexts}

Four trisyllabic sequences have been claimed to involve potentially more complex sandhi changes, due to the so-called iterative process of tone sandhi application (e.g., Chen, 2000). Note that the iterative process of sandhi application stems from the assumption in the literature that tone sandhi in Tianjin Mandarin involves the categorical change of one lexical tone to another, which leads to iterative sandhi application due to a new sandhi context resulting from the first round of sandhi application.

Given that T3T3 sandhi applies both when left aligned and right aligned, while T1T1 and T4T1 show sandhi change only when right aligned, we examined the possibilities listed in Table 9, where the bolded cases have been reported in the literature. Our results should shed light on two issues. One concerns the directionality of tone sandhi application when both directions provide sandhi contexts. The other concerns iterative sandhi application. For ease of exposition, we followed the sandhi rules claimed in the literature, and described the targeted outputs as results of the iterativity of sandhi application where the intermediate step would create a new tone sandhi context (i.e., if tone sandhi indeed involved categorical change of one lexical tone to another). Statistical results were shown in Tables 10-12.

\subsubsection{T3ТЗT3}

For the combination T3ТЗТ3, both directions of sandhi application are possible. According to the claimed rules in the literature, both T2T2T3 (from the left) and T3T2T3 (from the right) are possible outputs, where a chain effect is expected if the sandhi rule is applied from the left edge through an intermediate stage T2T3T3. Fig. 7 compares the three possible outcomes (Fig. 7a from left; Fig. 7b from right). As can be seen from Fig. 7, T3T3 sandhi was more likely to be applied from the left edge rather than from the right.

For the left-aligned sandhi application possibilities (Fig. 7a), T3T3T3 was similar to both T2T3T3 and T2T2T3, but was not completely neutralized with either. T3T3T3 and T2T3T3 were significantly different in terms of the mean f0 of the first tone. (See significant results for T3T3T3 vs. T2T3T3 in Table 10a.) T3T3T3 and T2T2T3 differed even more. There were significant differences in the overall fo mean and slope of both the first and second tones. (See significant results for T3T3T3 vs. T2T2T3 in Table 10a.) However, given the similarity of the contour shapes, it is likely that the second T3 changed to T2 in T3T3T3, although it is difficult to pin down that there was sandhi application over the second T3 given that the two contours were nevertheless quite different.

Turning to the right-aligned sandhi possibility (Fig. 7b), T3T3T3 and T3T2T3 were significantly different in the overall f0 mean and the slope for both the first and second tones. (See significant results of the intercept for T3T3T3 vs. T3T2T3 in Table 10b.) The significant and salient fo differences between the two tonal sequences suggest that T3 sandhi was unlikely to be applied from the right edge.

Table 9

Possible targeted outputs of complex tonal contexts according to the literature. The bolded items for patterns reported in the literature.

\begin{tabular}{|c|c|c|c|c|}
\hline & From the left & & From the right & \\
\hline \multirow[t]{2}{*}{ ТЗТЗТ3 } & (1st Round) & (2nd Round) & Т3Т2Т3 & \\
\hline & Т2т3т3 & T2Т2T3 & & \\
\hline \multirow[t]{2}{*}{ T3T1T1 } & No sandhi & & (1st Round) & (2nd Round) \\
\hline & & & Т3Т3Т1 & T2T3T1 \\
\hline T1T1T1 & No sandhi & & T1T3T1 & \\
\hline T4T1T1 & No sandhi & & T4T3T1 & \\
\hline
\end{tabular}


Table 10

Results of growth curve analyses for T3T3T3 vs. T2T3T3/T3T2T3/T2T2T3.

\begin{tabular}{|c|c|c|c|c|}
\hline & a. Left-aligned & & b. Right-aligned & \\
\hline & $\begin{array}{l}\text { ТЗТЗТ3 vs. Т2ТЗТ3 } \\
\text { 1st Tone }\end{array}$ & & $\begin{array}{l}\text { ТЗТЗТ3 vs. ТЗТ2Т3 } \\
\text { 1st Tone }\end{array}$ & $\begin{array}{l}\text { ТЗТЗТ3 vs. Т2ТЗТ3 } \\
\text { 2nd Tone }\end{array}$ \\
\hline \multirow[t]{2}{*}{ Intercept } & Estimate $=0.21$ & & Estimate $=0.38$ & Estimate $=0.85$ \\
\hline & $t=4.97, p<0.001$ & & $t=6.89, p<0.001$ & $t=20.06, p<0.001$ \\
\hline Slope & n.s. & & $\begin{array}{l}\text { Estimate }=0.39 \\
t=2.53, p<0.05\end{array}$ & $\begin{array}{l}\text { Estimate }=-0.99 \\
t=-11.61, p<0.001\end{array}$ \\
\hline \multirow[t]{3}{*}{ Quadratic } & n.s. & & n.s. & n.s. \\
\hline & ТЗТ3Т3 vs. Т2Т2Т3 & & & \\
\hline & 1st Tone & 2nd Tone & & \\
\hline Intercept & $\begin{array}{l}\text { Estimate }=-0.12 \\
t=-4.38, p<0.001\end{array}$ & $\begin{array}{l}\text { Estimate }=0.47 \\
t=7.88, p<0.001\end{array}$ & & \\
\hline Slope & $\begin{array}{l}\text { Estimate }=-0.23 \\
t=-2.49, p<0.05\end{array}$ & $\begin{array}{l}\text { Estimate }=0.52 \\
t=6.26, p<0.001\end{array}$ & & \\
\hline Quadratic & n.s. & n.s. & & \\
\hline
\end{tabular}

Table 11

Results of growth curve analyses for T3T1T1 vs. T3T3T1/T2T3T1.

\begin{tabular}{|c|c|c|c|c|}
\hline & \multicolumn{2}{|c|}{$\begin{array}{l}\text { a. Left-aligned } \\
\text { T3T1T1 vs. T3Т3T1 }\end{array}$} & \multicolumn{2}{|l|}{$\begin{array}{l}\text { b. Right-aligned } \\
\text { T3T1T1 vs. Т2Т3T1 }\end{array}$} \\
\hline & 1st Tone & 2nd Tone & 1st Tone & 2nd Tone \\
\hline Intercept & n.s. & $\begin{array}{l}\text { Estimate }=0.46 \\
t=14.32, p<0.001\end{array}$ & $\begin{array}{l}\text { Estimate }=-0.72 \\
t=-20.30, p<0.001\end{array}$ & $\begin{array}{l}\text { Estimate }=0.24 \\
t=11.48, p<0.001\end{array}$ \\
\hline Slope & $\begin{array}{l}\text { Estimate }=0.98 \\
t=7.00, p<0.001\end{array}$ & $\begin{array}{l}\text { Estimate }=-1.20 \\
t=-14.39, p<0.001\end{array}$ & $\begin{array}{l}\text { Estimate }=-0.94 \\
t=-6.70, p<0.001\end{array}$ & $\begin{array}{l}\text { Estimate }=-1.12 \\
t=-13.23, p<0.001\end{array}$ \\
\hline Quadratic & n.s. & n.s. & n.s. & $\begin{array}{l}\text { Estimate }=0.30 \\
t=3.55, p<0.001\end{array}$ \\
\hline
\end{tabular}

Table 12

Results of growth curve analyses for T1T1T1 vs. T1T3T1 and T4T1T1 vs. T4T3T1. Bolded items for tones under comparison.

\begin{tabular}{lll}
\hline & T1T1T1 vs. T1T3T1 & T4T1T1 vs. T4T3T1 \\
\hline Intercept & Estimate $=-0.40, t=-14.23, p<0.001$ & Estimate $=-0.96, t=-16.26, p<0.001$ \\
Slope & Estimate $=-0.62, t=-6.77, p<0.001$ & Estimate $=-0.54, t=-7.04, p<0.001$ \\
Quadratic & n.s. & n.s. \\
\hline
\end{tabular}

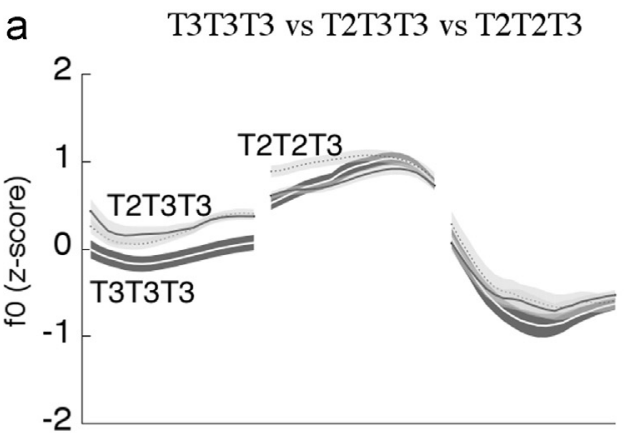

Normalized Time

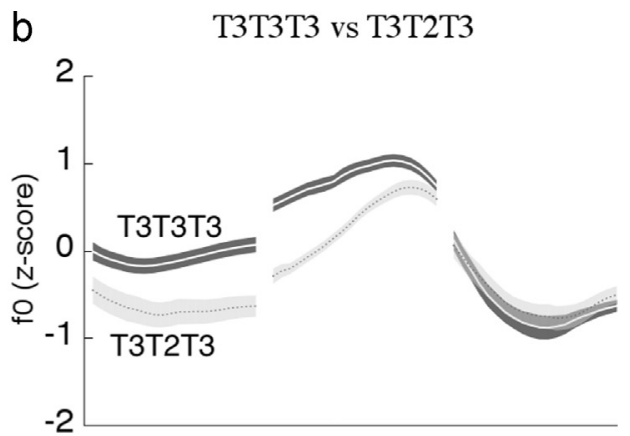

Normalized Time

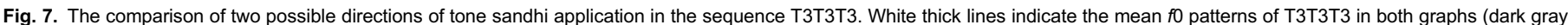

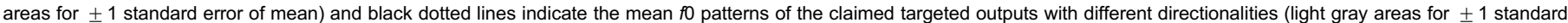
error of mean). Graph (a) indicates the left-initial direction and Graph (b) the right-initial direction. Normalized time. 


\subsection{2. $T 3 T 1 T 1$}

For T3T1T1, the literature has claimed iterative sandhi application initiated from the right edge through an intermediate stage T3T3T1 which in turn changes to T2T3T1, as shown in the second row of Table 9. In Fig. 8, the surface f0 pattern of T3T1T1 was compared to that of both potential outputs.

First, in Fig. 8, the first T3 in T3T1T1 was realized with a low-falling contour, which was significantly different from the rising f0 over T2 or T3. (See significant results in the slopes of the first tone for T3T1T1 vs. T3T3T1 and T3T1T1 vs. T2T3T1 in Table 11.) Second, the middle tone in T3T1T1 was realized with a rising $f 0$ contour, which indicates the application of tone sandhi here (compared to Fig. 3a). However, the middle T1 was not fully neutralized with the claimed output T3 in either T3T3T1 or T2T3T1. (See significant results for T3T1T1 vs. T3T3T1 and T3T1T1 vs. T2T3T1 in Table 11.) This suggests one-step tone sandhi from the right edge for T3T1T1, without any chain effect.

\subsection{3. $T 1 T 1 T 1$ and $T 4 T 1 T 1$}

For both T1T1T1 and T4T1T1, only one-step sandhi application from the right edge has been proposed in the literature. Fig. 9 illustrates $f 0$ realization of the two sequences, compared to their respective claimed outputs T1T3T1 (Fig. 9a) and T4T3T1 (Fig. 9b).

In both cases, sandhi application from the right edge was confirmed, again with no complete neutralization involved. Fig. 9a shows that the middle T1 was realized with a rising f0, suggesting the application of T1T1 tone sandhi from the right edge of the trisyllabic constituent. However, it was still not neutralized with its claimed targeted output T3, as suggested by the significant differences between the middle T1 and T3. (See significant results for T1T1T1 vs. T1T3T1 in Table 12.) Similarly, tone sandhi in T4T1T1 also seemed to be applied from the right edge (Fig. 9b), without complete tonal neutralization. (See significant results for T4T1T1 vs. T4T3T1 in Table 12.)

\subsection{Discussion}

For trisyllabic sequences, we were interested in the issue of directionality and iterativity of tone sandhi application. We separated our data into two sets. One concerns directionality of tone sandhi application in simple contexts where only one round of sandhi application is possible. We varied the position of the sandhi sequences, either to the left or to the right edge of a trisyllabic tone sequence. What has been claimed in the literature is that in such contexts, tone sandhi in Tianjin Mandarin applies consistently regardless of the positional alignment of the tonal sequences (e.g., Li \& Liu, 1985; Chen, 2000; Ma, 2005; Wee et al., 2005). Our results, however, did not support this observation. Our data showed that tone sandhi application over T1T1 and T4T1 sequences was only possible when these disyllabic sequences were aligned to the right edge of a trisyllabic constituent; while the T3T3 sequence triggered consistent application of sandhi changes regardless of its position within a trisyllabic utterance.

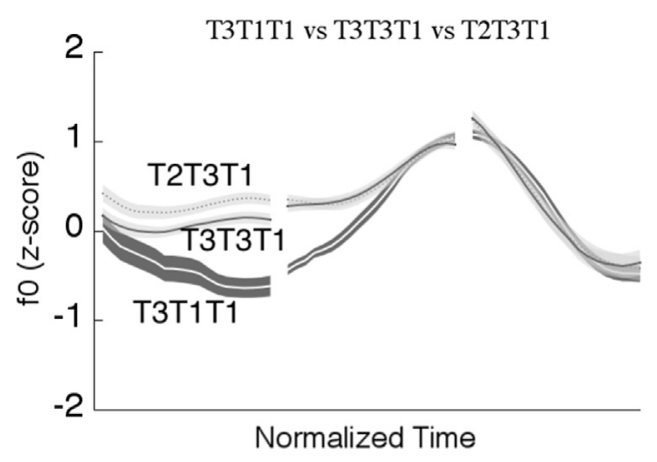

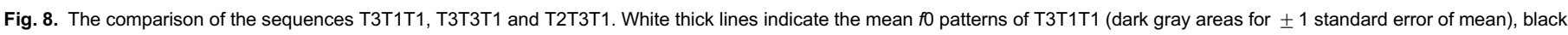

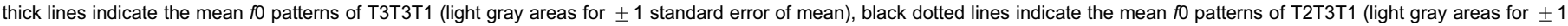
standard error of mean). Normalized time.
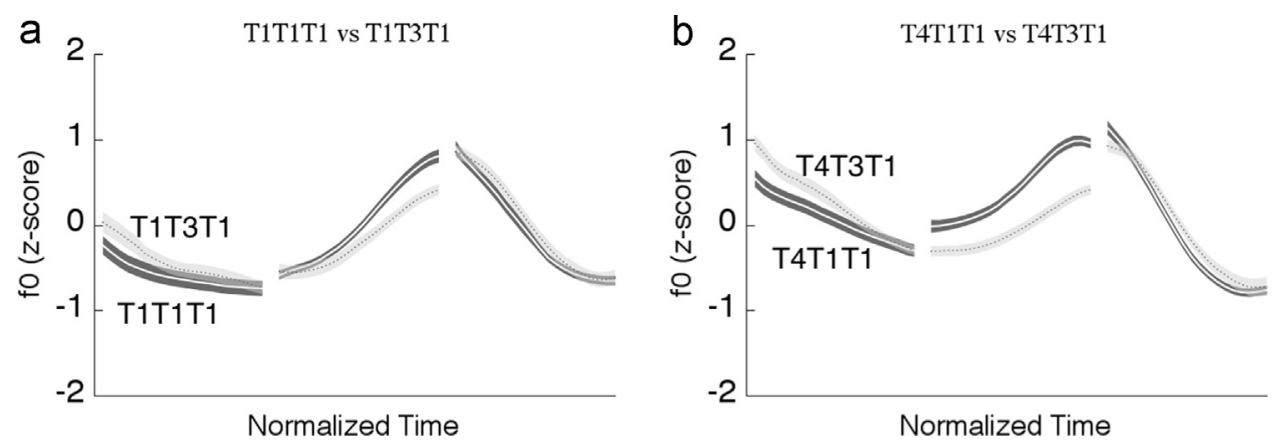

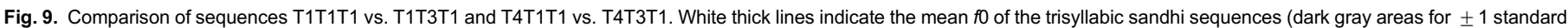
error of mean) and black dotted lines for the mean $f 0$ of the claimed targeted outputs (light gray areas for \pm 1 standard error of mean). Normalized time. 
Our second set of data examined complex sandhi contexts, where the literature has claimed both different directionalities of sandhi application as well as iterative sandhi processes due to the derived sandhi context (i.e., after an initial sandhi application process over the sequence). Two findings are to be noted. One is that we indeed found directional constraints on sandhi application. For T3T3T3 sequences, we observed only left-initiated tone sandhi application, in sharp contrast with the flexibility of T3 sandhi in the simple sandhi contexts. For the T1T1 and T4T1 sequences, we confirmed our observation in the simple contexts where tone sandhi was found to apply only when they were right aligned.

The non-neutralization of sandhi application was further confirmed in our trisyllabic data. We have shown that the fo realization of most trisyllabic sandhi combinations was significantly different from the claimed targeted outputs. If categorical change of one lexical tone to another was truly involved in tone sandhi, we would have expected all trisyllabic tone sandhi sequences to be realized exactly as the claimed targeted outputs. This, however, was not borne out. Furthermore, no iterativity of sandhi application was observed in our data. This lends further evidence to the argument that tone sandhi does not involve the categorical change of one lexical tone to another, which otherwise could have created a newly-derived sandhi context for another round of sandhi application.

\section{General discussion and conclusions}

This study illustrated the rich layers of lexical tone variability induced by different local contextual tonal variation processes, with empirical evidence from Tianjin Mandarin. Two specific questions have been addressed concerning the received wisdom of tonal variation in Tianjin Mandarin: (1) How does the fo realization of a lexical tone vary as a function of different following tones within a disyllabic domain? (2) How are the disyllabic tone sandhi patterns realized in trisyllabic sequences?

\subsection{Tonal variation in disyllabic domain}

With regard to disyllabic sequences, we aimed to fully understand the various patterns of $f 0$ deviation due to different contextual tonal variation processes, namely tonal anticipatory coarticulation and tone sandhi. To this end, we investigated all possible combinations of the four lexical tones in the language. In particular, we zoomed into the effect of the following tones (on the second syllable) on the $f 0$ realization of the preceding tone (on the first syllable), because this is a comparable context to examine both tonal coarticulation and tone sandhi as Tianjin Mandarin shows right-dominant tone sandhi patterns.

With the technique of growth curve analysis (GCA), we were able to objectively quantify whether and how fo contours differ from each other in terms of the overall $f 0$ means, the general $f 0$ direction and the $f 0$ contour shape, as a function of the following lexical tones. GCA with linear mixed-effects modeling also helped to take better care of not only the time-varying nature of fo contours but also variation due to individual participants. The methodology thus enabled us to better observe the $f 0$ variation and gain further understanding of the different sources of $f 0$ variation.

Two patterns emerged from the data, as summarized in Table 13. The first is that all significant fo variation observed over the first tone is triggered by a low-register lexical tone in Tianjin Mandarin (i.e., T1 or T3). T1 induces a consistent contour raising effect, while T3 exerts a more general raising effect on the preceding tones (except for T1 followed by T3). This in part confirms the findings of Zhang and Liu (2011), which only examined however the anticipatory tonal coarticulation in T1T3, T2T3, T4T3, and T2T1, and reported a significant raising effect only in T4T3. Our study, with all tonal combinations included and more powerful statistical analyses, showed that there was also a subtle but significant raising effect in T2T1, T3T1 and T2T3.

The question that arises is why both T1 and T3 tend to raise the preceding lexical tones? Within the Sinitic family, Xu (1997) reported a rather subtle anticipatory raising effect due to the low onset of the following tone, with data from Standard Chinese. In the case of Tianjin Mandarin, though a closely related Mandarin dialect, the raising effect seems to be dialect-specific. T1 and T2 are not that different in terms of their initial fo height. If anticipatory raising was purely phonetic due to the onset $f 0$ value of the following tone, we should have observed similar anticipatory raising effects. Our results, however, showed that they behaved completely differently in their effects on preceding tones. It is probably the tonal register (i.e., the low register in T1 and T3) that has played a role in conditioning anticipatory raising, suggesting the possibility of phonologically-conditioned anticipatory raising effects. It is to be noted

Table 13

Summary of the contexts and tonal variability type of first tone within a disyllabic constituents.

\begin{tabular}{|c|c|c|c|c|c|}
\hline \multirow[t]{3}{*}{ 1st Tone } & & \multicolumn{4}{|l|}{ 2nd Tone } \\
\hline & & \multicolumn{2}{|l|}{ Low register } & \multicolumn{2}{|c|}{ High register } \\
\hline & & $\mathrm{T} 1$ & T3 & $\mathrm{T} 2$ & $\mathrm{~T} 4$ \\
\hline Low & $\mathrm{T} 1$ & Sandhi rising & No effect & No effect & No effect \\
\hline register & T3 & $\begin{array}{l}\text { Anticipatory } \\
\text { rising }\end{array}$ & Sandhi raising & No effect & No effect \\
\hline \multirow[t]{2}{*}{$\begin{array}{l}\text { High } \\
\quad \text { register }\end{array}$} & $\mathrm{T} 2$ & $\begin{array}{l}\text { Anticipatory } \\
\text { rising }\end{array}$ & $\begin{array}{l}\text { Anticipatory } \\
\text { raising }\end{array}$ & No effect & No effect \\
\hline & $\mathrm{T} 4$ & Sandhi rising & $\begin{array}{l}\text { Anticipatory } \\
\text { raising }\end{array}$ & No effect & No effect \\
\hline
\end{tabular}


that significant anticipatory effects have also been reported for Malaysian Hokkien (Chang \& Hsieh, 2012), where carryover and anticipatory tonal coarticulation show similar magnitude due to the final prominence of the following syllable. These language-specific patterns contribute to the typology of contextual tonal variation, with data that challenge the general asymmetrical effects of tonal coarticulation (with greater carryover effects than anticipatory effects) observed in the literature (see Chen, 2012 for a review).

Second, we observed that for the sequences T1T1, T4T1 and T3T3, they either changed the f0 trajectory (in the case of T1T1 and T4T1) or substantially raised the overall f0 register (in the case of T3T3), which indeed seem appropriate to be characterized as due to tonal sandhi (as claimed in the literature). For the other four sequences (i.e., T2T1, T3T1, T2T3, T4T3), the lexical tones were realized with an $f 0$ contour that actually resembles the canonical realizations of the tones despite significant $f 0$ deviation. Therefore it is not clear whether tone sandhi has been applied or whether they are better accounted for as anticipatory tonal coarticulation.

Previous impressionistic studies have claimed that T4T4 also undergoes sandhi change to T1T4 (e.g., Li \& Liu, 1985; Hung, 1987; Tan, 1987; Zhang, 1987; Chen, 2000; J. Wang, 2002; Ma, 2005; Hyman, 2007). Our data, however, did not show any significant f0 variation over T4 due to the following T4. If T4T4 underwent sandhi change, the first T4 should have surfaced with a low-register falling $\mathrm{f0}$. On the contrary, Fig. 2d shows that the first T4 in T4T4 was realized with a high-register falling contour, similar to the T4 in T4T2 and T4T3. This is consistent with findings in recent studies (e.g., Liu \& Gao, 2003; Zhang \& Liu, 2011), which argued that the T4T4 sandhi process has become "obsolete", possibly due to the influence from Standard Chinese, where there is no tone sandhi over the T4T4 sequence.

When followed by T2 or T4, T3 was realized with a low-falling contour, resembling the canonical realization of T1 in isolation. This has led to the claim that T3T2 and T3T4 also involve tone sandhi change into the lexical T1 (e.g., Wee et al., 2005) or into a half T3 (Zhang \& Liu, 2011). ${ }^{1} \mathrm{Ma}$ and Jia (2006) showed that listeners could reliably distinguish T3T2 from T1T2 and T3T4 from T1T4. Moreover, it is important to note that in our data, neither T2 nor T4 seems to introduce any anticipatory effect on its preceding tones unlike as observed for T1 and T3. We thus adopt the view that the half-realized T3 is due to tonal reduction in connected speech, which seems to be a more general phonetic reduction of dipping tone in connected speech as is also evident in Standard Chinese. However, as pointed out by one reviewer, we cannot rule out the possibility that tonal reduction is phonologized and should be classified as tone sandhi, as proposed in Zhang and Liu (2011).

There have been some attempts in the last decades to establish objective criteria to distinguish between tone sandhi and tonal coarticulation. Shen (1992) proposes a three-way distinction between the two types of tonal variation. (1) Tone sandhi is constrained by language-specific morphophonemics, while tonal coarticulation is a language-independent mechanism. (2) Tone sandhi is either assimilatory or dissimilatory, while tonal coarticulation is only assimilatory. (3) Tone sandhi involves tonal identity change from one tone to another while the tonal identity is maintained in tonal coarticulation. None of these criteria, however, really succeeded in differentiating the two processes, as also discussed in Chen (2000). First, tone sandhi and tonal coarticulation could both be affected by morphophonemics as suggested in Wu (1985). Second, cross-linguistic evidence has shown that tonal coarticulation could be either assimilatory or dissimilatory (e.g., Gandour et al., 1994 for Thai; Xu, 1997 for Beijing Mandarin; Zhang \& Liu, 2011 for Tianjin Mandarin; Chang \& Hsieh, 2012 for Malaysian Hokkien). Third, tone sandhi does not always involve tonal identity change. For example, in the T1T1 sequence, our results show that the first T1 is clearly not changed from T1 to T3 as claimed in the literature, but the magnitude of the change suggests the possibility of phonologization of such an anticipatory raising effect. These observations led to the proposition in Chen (2000) that there is actually "no essential difference" between the two processes.

As the boundary between tone sandhi and tonal coarticulation is not straightforward and proves difficult to establish, this makes it even more important for us to first objectively observe the patterns of $f 0$ variation as we have done in the current study. Without this, any discussion over the difference between these two variation types is doomed to be without foundation.

Through the extensive comparisons of the full dataset with all four lexical tones in both the first and second syllables, we can see that the raising effects due to T3 and T1 indeed need to be further differentiated. The T3 category across Mandarin dialects is known for its sandhi process over a T3T3 sequence, regardless of the specific f0 contour of the lexical tone category (Shih, 1986). This process has been proposed to date back to the 16th century (Mei, 1977; also see discussion in Zhang, 2010). As for T1T1 and T4T1, a significant raising effect was observed, which is in contrast to the more subtle raising effect of T1 over T2T1 and T3T1. We believe that this difference is related to the saliency of cues for $f 0$ raising before T1. In the case of two falling tones, i.e., T1 and T4, the raising effect can be effectively implemented, which probably led to an enhanced realization of fo raising and consequently a phonologized contextual tonal change; while in the case of T2 and T3, both with a rising fo contour in the canonical fo shape, there is no further room to signal the raising due to $\mathrm{T} 1$, which therefore remains a more subtle coarticulatory effect.

The raising effects due to T3 and T1 can be further teased apart in terms of how closely the sandhi outputs resemble a lexical tone in the native system. T3T3 is a near-merger (following Yu, 2007), in that the derived T3 sandhi realization shows an almost merged f0 pattern to that of a lexical high-register rising tone, i.e., T2 in T2T3. This explains why in the literature T3T3 is described as changing into T2T3. T1T1 and T4T1, however, are clearly no-mergers. Their derived sandhi outputs are clearly different from any of the lexical tones in the system, in contradiction to the claim that they change to T3/T2T1 and T2T1 respectively. Our study, thus far, is the first to illuminate this distinction. An interesting question that is currently addressed in a perception study is how such different patterns of tone sandhi affect the way lexical tones are processed in online speech recognition.

\footnotetext{
${ }^{1}$ The falling contour of T3 is also comparable to the half low tone realization in Standard Mandarin (Chao, 1968), where the final rise of the dipping T3 is always absent in nonprepausal positions (but present when followed by a neutral tone as discussed in details in Chen \& Xu, 2006 and Prom-on, Liu \& Xu, 2012).
} 


\begin{tabular}{|c|c|c|c|}
\hline & \multirow[t]{2}{*}{$\begin{array}{l}\text { Sandhi variation over } \\
\text { disyllabic sequences }\end{array}$} & \multicolumn{2}{|c|}{$\begin{array}{l}\text { Directionality over } \\
\text { trisyllabic sequences }\end{array}$} \\
\hline & & $\begin{array}{l}\text { Simple } \\
\text { contexts }\end{array}$ & $\begin{array}{l}\text { Complex } \\
\text { contexts }\end{array}$ \\
\hline Т3Т3 & Near-merger & $\begin{array}{l}\text { From both } \\
\text { directions }\end{array}$ & $\begin{array}{l}\text { From the } \\
\text { left edge }\end{array}$ \\
\hline T1T1 & No-merger & \multirow{2}{*}{\multicolumn{2}{|c|}{ From the right edge }} \\
\hline T4T1 & No-merger & & \\
\hline
\end{tabular}

\subsection{Tonal variation in trisyllabic domain}

Our disyllabic data established firmly that tone sandhi in Tianjin Mandarin should not be characterized as the categorical change of one lexical tone to another, confirming earlier findings in Zhang and Liu (2011) and Li and Chen (2012). This finding also led to the absolute necessity of further investigation on trisyllabic tone sandhi patterns in Tianjin Mandarin, which have raised numerous critical issues in the theoretical treatment of tone sandhi in general (e.g., Chen, 2000). Our approach was to first investigate the empirical foundation of the reported complexity in Tianjin Mandarin tone sandhi over trisyllabic sequences. To this end, we have analyzed the fo realization of trisyllabic tonal combinations with two more specific goals in mind.

The first was on the directionality of sandhi application in simple tonal contexts with only one disyllabic sequence involving potential tone sandhi. The three tone sandhi sequences (i.e., T1T1, T4T1, and T3T3) were embedded in trisyllabic constituents, either left-aligned (e.g., T1T1Tx) or right-aligned (e.g., TxT1T1). Different from the claims in the literature, we observed that while T3T3 sandhi applied in either direction, T1T1 and T4T1 surfaced with their predicted sandhi f0 contours only when they were right aligned. This is the very first experimental finding on Tianjin trisyllabic tone sandhi. Our finding therefore greatly simplifies the hitherto claimed complex directionality of tone sandhi in Tianjin Mandarin.

Our second goal was to examine further the claimed iterativity of sandhi application, which refers to the application of tone sandhi over derived sandhi contexts due to an earlier round of tone sandhi application. Specifically, we examined the $f 0$ contours of the underlying sequences of T3T3T3, T3T1T1, T1T1T1, and T4T1T1. Interestingly, we noticed a further directionality restriction over T3T3T3 sequence where T3 sandhi seemed to only apply from the left edge, resulting in the ambiguity between T3 $\mathrm{T}_{\text {sandhi }} \mathrm{T}_{\text {sandhi }} \mathrm{T} 3$. Either pattern, however, does not have to involve iterative sandhi application. Furthermore, no iterativity of sandhi application in T3T1T1 was found, even though it has been claimed in the literature that the change of T1T1 to T3T1 creates an intermediate stage T3T3T1 which triggers a further sandhi change into T2T3T1. For the other two tonal sequences concerning T1T1 (i.e., T1T1T1 and T4T1T1), our data only showed one-step tone sandhi application from the right-aligned disyllabic sequences. In short, no iterative sandhi application can be confirmed in our data.

Taking together both disyllabic and trisyllabic data, we have observed two types of tone sandhi in Tianjin Mandarin, as summarized in Table 14. T3T3 is a near-merge case. Its sandhi output T3 $3_{\text {sandhi }}$ T3 shows an almost merged f0 contour with the lexical tonal sequence of T2T3. In a simple trisyllabic sandhi context, this sandhi process can occur from either direction regardless of its alignment within the constituent. However, in a complex trisyllabic sandhi context, T3T3 surfaces with a pattern that suggests only left-aligned sandhi application, resulting in an f0 contour that can be characterized as $\mathrm{T}_{\text {sandhi }} \mathrm{T} 3 \mathrm{~T} 3$ or T3 ${ }_{\text {sandhi }} \mathrm{T} 3_{\text {sandhi }} \mathrm{T} 3$. T1 T1 and T4T1 can be classified as no-mergers, given that their sandhi realizations do not resemble the f0 contours of any of the lexical tones in the language. In contrast to T3T3, tone sandhi in T1T1 and T4T1 is applied only when the disyllabic sequence is right aligned regardless of whether the embedding trisyllabic constituent provides a simple or complex sandhi context. No iterativity of sandhi application was observed in any of these tonal sequences.

This study therefore provides a substantial amount of experimental data that greatly simplify the complex and paradoxical tone sandhi patterns reported in the literature (e.g., Li \& Liu, 1985; Hung, 1987; Tan, 1987; Zhang, 1987; Chen, 2000; J. Wang, 2002; Ma, 2005; Wee et al., 2005; Zhang \& Liu, 2011). We believe that our findings are not only of major empirical significance, but will also contribute to the further development of theories of tonal variation in general, as any good theory needs to be based upon solid empirical evidence. A cautionary note is that our data are representative of speakers born in the 1980s. It is possible that those tone sandhi patterns claimed in the literature can only be observed in older speakers, which then requires relevant experimental data in the future. If any generational difference is verified, it would be important to investigate the mechanisms that explain the changing sandhi patterns observed in old vs. young Tianjin Mandarin speakers as well as the implication of such tonal change mechanisms for language evolution in general.

\section{Acknowledgments}

We thank the editor and two anonymous reviewers for their constructive suggestions. We thank Larry Hyman, Vincent van Heuven and Jenny de Sonneville, as well as the participants at the $3^{\text {rd }}$ International Symposium on Tonal Aspects of Language in 2012 for their comments on an earlier report of this work. We are also grateful to Shipeng Shao, Zi Wang and Ting Zou for serving as our 
language consultants and all the speakers who participated in our experiment. This research is supported by CSC scholarship and LUF grant to the first author as well as the NWO VIDI grant (016084338) and the ERC Starting grant (206198) to the second author.

\section{Appendix}

The full list of disyllabic and trisyllabic words used in the experiment are given below.

Disyllabic word list:

\begin{tabular}{|c|c|c|c|c|c|c|}
\hline \multirow{3}{*}{$\begin{array}{l}\text { Tonal sequences } \\
\text { T1T1 }\end{array}$} & \multicolumn{6}{|c|}{ Morpho-syntactic structures } \\
\hline & \multicolumn{2}{|l|}{ Compound } & \multicolumn{2}{|c|}{ Modifier+head } & \multicolumn{2}{|l|}{ Verb + object } \\
\hline & $\begin{array}{l}\text { 爹妈 } \\
\mathrm{die}^{1} \mathrm{ma}^{1}\end{array}$ & parents & $\begin{array}{l}\text { 家猫 } \\
\mathrm{jia}^{1} \mathrm{mao}^{1}\end{array}$ & domestic cat & $\begin{array}{l}\text { 弯腰 } \\
\text { wan }^{1} \text { yao }^{1}\end{array}$ & to bend down \\
\hline T1T2 & $\begin{array}{l}\text { 规模 } \\
\text { gui }^{1} \mathrm{mo}^{2}\end{array}$ & scale & $\begin{array}{l}\text { 歌迷 } \\
\mathrm{ge}^{1} \mathrm{mi}^{2}\end{array}$ & fans & $\begin{array}{l}\text { 猜谜 } \\
\text { cai }^{1} \mathrm{mi}^{2}\end{array}$ & to guess a riddle \\
\hline T1T3 & $\begin{array}{l}\text { 枢纽 } \\
\text { shu }^{1} \text { niu }^{3}\end{array}$ & hub & $\begin{array}{l}\text { 徙米 } \\
\mathrm{cao}^{1} \mathrm{mi}^{3}\end{array}$ & brown rice & $\begin{array}{l}\text { 推理 } \\
\text { tui }{ }^{1} i^{3}\end{array}$ & to reason \\
\hline T1T4 & $\begin{array}{l}\text { 归纳 } \\
\text { gui }^{1} \mathrm{na}^{4}\end{array}$ & to conclude & $\begin{array}{l}\text { 闺蜜 } \\
\text { gui1 } \mathrm{mi}^{4}\end{array}$ & girlfriends & $\begin{array}{l}\text { 揭密 } \\
\mathrm{jie}^{1} \mathrm{mi}^{4}\end{array}$ & to reveal a secret \\
\hline $\mathrm{T} 2 \mathrm{~T} 1$ & $\begin{array}{l}\text { 拿捏 } \\
\mathrm{na}^{2} \mathrm{nie}^{1}\end{array}$ & to ponder & $\begin{array}{l}\text { 白猫 } \\
\mathrm{bai}^{2} \mathrm{mao}^{1}\end{array}$ & white cat & $\begin{array}{l}\text { 行医 } \\
x_{\text {ing }}{ }^{2} \mathrm{yi}^{1}\end{array}$ & to practice medicine \\
\hline $\mathrm{T} 2 \mathrm{~T} 2$ & $\begin{array}{l}\text { 皮毛 } \\
\mathrm{pi}^{2} \mathrm{mao}^{2}\end{array}$ & fur & $\begin{array}{l}\text { 活埋 } \\
\text { huo }^{2} \text { mai }^{2}\end{array}$ & to bury alive & $\begin{array}{l}\text { 回瞈 } \\
\mathrm{hui}^{2} \mathrm{mou}^{2}\end{array}$ & to look back \\
\hline T2T3 & $\begin{array}{l}\text { 涂抹 } \\
{t u^{2}}^{2} \mathrm{mo}^{3}\end{array}$ & to smear & $\begin{array}{l}\text { 鸟鸟 } \\
\text { tuo }^{2} \text { niao }^{3}\end{array}$ & ostrich & $\begin{array}{l}\text { 淘米 } \\
\mathrm{tao}^{2} \mathrm{mi}^{3}\end{array}$ & to wash rice \\
\hline $\mathrm{T} 2 \mathrm{~T} 4$ & $\begin{array}{l}\text { 稠密 } \\
\text { chou }^{2} \mathrm{mi}^{4}\end{array}$ & dense & $\begin{array}{l}\text { 胡闹 } \\
h u^{2} \text { nao }^{4}\end{array}$ & to make trouble & $\begin{array}{l}\text { 夺目 } \\
\text { duo }^{2} \mathrm{mu}^{4}\end{array}$ & dazzling \\
\hline T3T1 & $\begin{array}{l}\text { 扭捏 } \\
\text { niu }^{3} \text { nie }^{1}\end{array}$ & $\operatorname{coy}$ & $\begin{array}{l}\text { 奶妈 } \\
\mathrm{nai}^{3} \mathrm{ma}^{1}\end{array}$ & nanny & $\begin{array}{l}\text { 爽约 } \\
\text { shuang }^{3} \text { yue }^{1}\end{array}$ & to fail to keep an appointment \\
\hline Т3Т2 & $\begin{array}{l}\text { 楷模 } \\
\mathrm{kai}^{3} \mathrm{mo}^{2}\end{array}$ & model & $\begin{array}{l}\text { 铁牛 } \\
\text { tie }^{3} \text { niu }^{2}\end{array}$ & tractor & $\begin{array}{l}\text { 起针 } \\
\mathrm{qi}^{3} \mathrm{mao}^{2}\end{array}$ & to raise anchor \\
\hline Т3Т3 & $\begin{array}{l}\text { 子女 } \\
z i^{3} n \ddot{n}^{3}\end{array}$ & child & $\begin{array}{l}\text { 舞女 } \\
w u^{3} n \ddot{u}^{3}\end{array}$ & dancing girl & $\begin{array}{l}\text { 洗脑 } \\
\mathrm{xi}^{3} \mathrm{nao}^{3}\end{array}$ & to brainwash \\
\hline T3T4 & $\begin{array}{l}\text { 美妙 } \\
\mathrm{mei}^{3} \mathrm{miao}^{4}\end{array}$ & wonderful & $\begin{array}{l}\text { 果木 } \\
\mathrm{guo}^{3} \mathrm{mu}^{4}\end{array}$ & fruit tree & $\begin{array}{l}\text { 把脉 } \\
\mathrm{ba}^{3} \mathrm{mai}^{4}\end{array}$ & to take one's pulse \\
\hline T4T1 & $\begin{array}{l}\text { 触摸 } \\
\mathrm{chu}^{4} \mathrm{mo}^{1}\end{array}$ & to touch & $\begin{array}{l}\text { 后妈 } \\
\text { hou }^{4} \mathrm{ma}^{1}\end{array}$ & step mother & $\begin{array}{l}\text { 喂猫 } \\
w^{4}{ }^{4} \mathrm{mao}^{1}\end{array}$ & to feed the cat \\
\hline T4T2 & $\begin{array}{l}\text { 计谋 } \\
\mathrm{ji}^{4} \mathrm{mou}^{2}\end{array}$ & stratagem & $\begin{array}{l}\text { 亚麻 } \\
\mathrm{ya}^{4} \mathrm{ma}^{2}\end{array}$ & linen & $\begin{array}{l}\text { 蓄谋 } \\
\mathrm{xu}^{4} \mathrm{mou}^{2}\end{array}$ & to premeditate \\
\hline T4T3 & $\begin{array}{l}\text { 购买 } \\
\text { gou }^{4} \mathrm{mai}^{3}\end{array}$ & to buy & $\begin{array}{l}\text { 密码 } \\
\mathrm{mi}^{4} \mathrm{ma}^{3}\end{array}$ & password & $\begin{array}{l}\text { 喂奶 } \\
\text { wei }^{4} \text { nai }^{3}\end{array}$ & to breastfeed \\
\hline T4T4 & $\begin{array}{l}\text { 咒骂 } \\
\text { zhou }^{4} \mathrm{ma}^{4}\end{array}$ & to curse & $\begin{array}{l}\text { 内幕 } \\
n \mathrm{ei}^{4} \mathrm{mu}^{4}\end{array}$ & inside story & $\begin{array}{l}\text { 盗墓 } \\
\mathrm{dao}^{4} \mathrm{mu}^{4}\end{array}$ & to rob a grave \\
\hline
\end{tabular}

Trisyllabic list 1: $\sigma \sigma \sigma$

\begin{tabular}{|c|c|c|c|c|}
\hline Tonal sequences & Word 1 & & Word 2 & \\
\hline T1T1T1 & $\begin{array}{l}\text { 乌拉圭 } \\
\mathrm{wu}^{1} \mathrm{la}^{1} \mathrm{gui}^{1}\end{array}$ & Uruguay & $\begin{array}{l}\text { 撒哈拉 } \\
\mathrm{sa}^{1} \mathrm{ha}^{1} \mathrm{la}^{1}\end{array}$ & Sahara \\
\hline T1T1T2 & $\begin{array}{l}\text { 西班牙 } \\
\mathrm{xi}^{1} \text { ban }^{1} \mathrm{ya}^{2}\end{array}$ & Spain & $\begin{array}{l}\text { 阿拉伯 } \\
a^{1} l a^{1} b o^{2}\end{array}$ & Arab \\
\hline T1T1T3 & $\begin{array}{l}\text { 希拉里 } \\
x \mathrm{i}^{1} \mathrm{la}^{1} \mathrm{li}^{3}\end{array}$ & Hilary & $\begin{array}{l}\text { 巴哈马 } \\
\mathrm{ba}^{1} \mathrm{ha}^{1} \mathrm{ma}^{3}\end{array}$ & Bahamas \\
\hline T1T1T4 & $\begin{array}{l}\text { 伊拉克 } \\
\mathrm{yi}^{1} \mathrm{la}^{1} \mathrm{ke}^{4}\end{array}$ & Iraq & $\begin{array}{l}\text { 科威特 } \\
\mathrm{ke}^{1} \mathrm{wei}^{1} \mathrm{te}^{4}\end{array}$ & Kuwait \\
\hline $\mathrm{T} 1 \mathrm{~T} 2 \mathrm{~T} 1$ & $\begin{array}{l}\text { 昆德拉 } \\
\text { kun }^{1} \mathrm{de}^{2} \mathrm{la}^{1}\end{array}$ & Kundera & $\begin{array}{l}\text { 科伦坡 } \\
\mathrm{ke}^{1} \operatorname{lun}^{2} \mathrm{po}^{1}\end{array}$ & Colombo \\
\hline $\mathrm{T} 1 \mathrm{~T} 2 \mathrm{~T} 2$ & $\begin{array}{l}\text { 科摩罗 } \\
\mathrm{ke}^{1} \mathrm{mo}^{2} \mathrm{luo}^{2}\end{array}$ & Comoros & $\begin{array}{l}\text { 巴格达 } \\
\mathrm{ba}^{1} \mathrm{ge}^{2} \mathrm{da}^{2}\end{array}$ & Baghdad \\
\hline T1T2T3 & $\begin{array}{l}\text { 巴拿马 } \\
\mathrm{ba}^{1} \mathrm{na}^{2} \mathrm{ma}^{3}\end{array}$ & Panama & $\begin{array}{l}\text { 多明我 } \\
\text { duo }^{1} \mathrm{ming}^{2} \mathrm{wo}^{3}\end{array}$ & Domingo \\
\hline
\end{tabular}


T1T2T4

T1T3T1

T1T3T2

T1T3T3

T1T3T4

T1T4T1

T1T4T2

T1T4T3

T1T4T4

T2T1T1

T2T1T2

T2T1T3

T2T1T4

T2T2T1

T2T2T2

T2T2T3

T2T2T4

T2T3T1

T2T3T2

T2T3T3

T2T3T4

T2T4T1

T2T4T2

T2T4T3

T2T4T4

T3T1T1

T3T1T2

T3T1T3

T3T1T4

T3T2T1

T3T2T2

T3T2T3

T3T2T4
加拿大

$\mathrm{jia}^{1} \mathrm{na}^{2} \mathrm{da}^{4}$

安卡拉

$a n^{1} k a^{3} l a^{1}$

苏里南

$\mathrm{su}^{1} \mathrm{li}^{3} \mathrm{nan}^{2}$

托马里

tuo $\mathrm{ma}^{3} \mathrm{li}^{3}$

多普勒

duo ${ }^{1} \mathrm{pu}^{3} l \mathrm{e}^{4}$

菲律宾

$\mathrm{fei}^{1} \mathrm{IV}^{4} \mathrm{bin}^{1}$

喀麦隆

$\mathrm{ka}^{1} \mathrm{mai}^{4}$ long $^{2}$

哈勒姆

$\mathrm{ha}^{1} \mathrm{le}^{4} \mathrm{mu}^{3}$

伽利略

$\mathrm{jia}^{1} \mathrm{li}^{4}$ lü $\mathrm{e}^{4}$

尼加拉

$\mathrm{ni}^{2} \mathrm{jia}^{1} \mathrm{la}^{1}$

柏拉图

$b o^{2} l a^{1} t u^{2}$

博拉美

bo $^{2}$ la $^{1} \mathrm{mei}^{3}$

黎巴嫩

li $^{2}$ ba $^{1}$ nen $^{4}$

吉隆坡

$\mathrm{ji}^{2}$ long $^{2} \mathrm{po}^{1}$

婆罗门

$\mathrm{po}^{2} \mathrm{luo}^{2} \mathrm{men}^{2}$

德雷姆

$\mathrm{de}^{2} \mathrm{lei}^{2} \mathrm{mu}^{3}$

尤迪特

you ${ }^{2} \mathrm{di}^{2} \mathrm{te}^{4}$

牙买加

$\mathrm{ya}^{2} \mathrm{mai}^{3} \mathrm{jia}^{1}$

梅里达

$m e i^{2} i^{3} d^{2}$

劳卡鲁

$\mathrm{lao}^{2} \mathrm{ka}^{3} \mathrm{lu}^{3}$

伯努利

$\mathrm{bo}^{2} \mathrm{nu}^{3} \mathrm{li}^{4}$

摩纳哥

$\mathrm{mo}^{2} \mathrm{na}^{4} \mathrm{ge}^{1}$

罗纳德

luo ${ }^{2} \mathrm{na}^{4} \mathrm{de}^{2}$

伯克里

$b^{2} \mathrm{ke}^{4} l i^{3}$

维克特

$w_{e i^{2}} \mathrm{ke}^{4} \mathrm{te}^{4}$

塔波拉

ta ${ }^{3} \mathrm{bo}^{1} \mathrm{la}^{1}$

比基尼

$\mathrm{bi}^{3} \mathrm{ji}^{1} \mathrm{ni}^{2}$

果哥里

guo $^{3} \mathrm{ge}^{1} \mathrm{li}^{3}$

法拉利

$\mathrm{fa}^{3} \mathrm{la}^{1} \mathrm{li}^{4}$

海明威

hai $^{3}$ ming $^{2}$ wei $^{1}$

卡琳达

$\mathrm{ka}^{3} \operatorname{lin}^{2} \mathrm{da}^{2}$

马德里

$\mathrm{ma}^{3} \mathrm{de}^{2} \mathrm{li}^{3}$

马其顿

$\mathrm{ma}^{3} \mathrm{qi}^{2}$ dun ${ }^{4}$
Ankara

Surinam

Tomari

Doppler

Philippine

Cameroon

Haarlem

Galilei

Niagara

Plato

Polamer

Lebanon

Kuala Lumpur

Brahman

Dremu

Udeet

Jamaica

Merida

Lokarus

Bernoulli

Monaco

Ronald

Berkeley

Victor

Tabora

Bikini

Gogol

Ferrari

Hemingway

Kalinda

Madrid

Macedonia
匈牙利

xiong ${ }^{1} \mathrm{ya}^{2} \mathrm{li}^{4}$

詹姆斯

$\operatorname{zhan}^{1} \mathrm{mu}^{3} \mathrm{si}^{1}$

多里达

duo ${ }^{1} \mathrm{li}^{3} \mathrm{da}^{2}$

扎卡里

zha ${ }^{1} \mathrm{ka}^{3} \mathrm{li}^{3}$

冈比亚

gang ${ }^{1} \mathrm{bi}^{3} \mathrm{ya}^{4}$

阿克拉

$a^{1} k e^{4} l a^{1}$

乌克兰

$w u^{1} \mathrm{ke}^{4} \operatorname{lan}^{2}$

安道尔

$a n^{1} \mathrm{dao}^{4} \mathrm{er}^{3}$

巴洛克

ba $^{1}$ luo $^{4} \mathrm{ke}^{4}$

达拉斯

$\mathrm{da}^{2} \mathrm{la}^{1} \mathrm{si}^{1}$

德黑兰

$\mathrm{de}^{2}$ hei $^{1} \operatorname{lan}^{2}$

卢森堡

$\mathrm{lu}^{2} \operatorname{sen}^{1} \mathrm{bao}^{3}$

明斯克

$\operatorname{ming}^{2} \mathrm{si}^{1} \mathrm{ke}^{4}$

俄罗斯

$\mathrm{e}^{2}$ luo $^{2} \mathrm{si}^{1}$

迪德罗

$\mathrm{di}^{2} \mathrm{de}^{2} l u \mathrm{o}^{2}$

尼泊尔

$\mathrm{ni}^{2} \mathrm{bo}^{2} \mathrm{er}^{3}$

格兰特

$\mathrm{ge}^{2} \operatorname{lan}^{2} \mathrm{te}^{4}$

莱比锡

$l a i^{2} b i^{3} x i^{1}$

图瓦卢

$\mathrm{tu}^{2} \mathrm{wa}^{3} l \mathrm{u}^{2}$

伯里瓦

$\mathrm{bo}^{2} \mathrm{li}^{3} \mathrm{wa}^{3}$

维也纳

$w \mathrm{i}^{2} \mathrm{ye}^{3} \mathrm{na}^{4}$

伯利兹

$\mathrm{bo}^{2} \mathrm{li}^{4} \mathrm{zi}^{1}$

卢旺达

$l^{2}{ }^{2}$ wang $^{4} \mathrm{da}^{2}$

尼日尔

$n i^{2} \mathrm{ri}^{4} \mathrm{er}^{3}$

华盛顿

hua $^{2}$ sheng $^{4}$ dun $^{4}$

美因兹

$\mathrm{mei}^{3} \mathrm{yin}^{1} \mathrm{zi}^{1}$

马拉维

$\mathrm{ma}^{3} \mathrm{la}^{1} \mathrm{wei}^{2}$

里斯本

$\mathrm{li}^{3} \mathrm{si}^{1} \mathrm{ben}^{3}$

索菲亚

suo $^{3}$ fei $^{1} \mathrm{ya}^{4}$

马尼拉

$\mathrm{ma}^{3} \mathrm{ni}^{2} \mathrm{la}^{1}$

所罗门

suo $^{3}$ luo $^{2}$ men $^{2}$

纽伦堡

niu $^{3}$ lun $^{2}$ bao $^{3}$

塔吉克

$\mathrm{ta}^{3} \mathrm{ji}^{2} \mathrm{ke}^{4}$
Hungary

James

Derrida

Zachry

Gambia

Accra

Ukraine

Andorra

Baroque

Dallas

Tehran

Luxembourg

Minsk

Russia

Diderot

Nepal

Grant

Leipzig

Tuvalu

Bolivar

Vienna

Belize

Rwanda

Niger

Washington

Mainz

Malawi

Lisbon

Sofia

Manila

Solomon

Nuremberg

Tajik 


\begin{tabular}{|c|c|c|c|c|}
\hline Т3Т3Т1 & $\begin{array}{l}\text { 卡米拉 } \\
\mathrm{ka}^{3} \mathrm{mi}^{3} \mathrm{la}^{1}\end{array}$ & Camilla & $\begin{array}{l}\text { 马耳他 } \\
\mathrm{ma}^{3} \mathrm{er}^{3} \mathrm{ta}^{1}\end{array}$ & Malta \\
\hline Т3Т3Т4 & $\begin{array}{l}\text { 柬埔寨 } \\
\text { jian }^{3} \mathrm{pu}^{3} \mathrm{zhai}^{4}\end{array}$ & Cambodia & $\begin{array}{l}\text { 雅典娜 } \\
\mathrm{ya}^{3} \operatorname{dian}^{3} \mathrm{na}^{4}\end{array}$ & Athena \\
\hline T3Т4T2 & $\begin{array}{l}\text { 普契尼 } \\
\mathrm{pu}^{3} \mathrm{qi}^{4} \mathrm{ni}^{2}\end{array}$ & Puccini & $\begin{array}{l}\text { 比利时 } \\
\mathrm{bi}^{3} \mathrm{li}^{4} \mathrm{shi}^{2}\end{array}$ & Belgium \\
\hline Т3Т4T3 & $\begin{array}{l}\text { 马六甲 } \\
\mathrm{ma}^{3} \mathrm{liu}^{4} \mathrm{jia}^{3}\end{array}$ & Malacca & $\begin{array}{l}\text { 马绍尔 } \\
\mathrm{ma}^{3} \mathrm{shao}^{4} \mathrm{er}^{3}\end{array}$ & Marshall \\
\hline T3Т4T4 & $\begin{array}{l}\text { 玛丽娜 } \\
\mathrm{ma}^{3} \mathrm{li}^{4} \mathrm{na}^{4}\end{array}$ & Marina & $\begin{array}{l}\text { 以色列 } \\
\mathrm{yi}^{3} \mathrm{se}^{4} \mathrm{lie}^{4}\end{array}$ & Isreal \\
\hline T4T1T3 & $\begin{array}{l}\text { 爱丁堡 } \\
\mathrm{ai}^{4} \text { ding }^{1} \mathrm{bao}^{3}\end{array}$ & Edinburgh & $\begin{array}{l}\text { 奥巴马 } \\
\mathrm{ao}^{4} \mathrm{ba}^{1} \mathrm{ma}^{3}\end{array}$ & Obama \\
\hline T4T1T4 & $\begin{array}{l}\text { 麦当娜 } \\
\text { mai }^{1} \text { dang }^{1} \mathrm{na}^{4}\end{array}$ & Madonna & $\begin{array}{l}\text { 奥斯陆 } \\
\mathrm{ao}^{4} \mathrm{si}^{1} \mathrm{lu}^{4}\end{array}$ & Oslo \\
\hline T4T2T1 & $\begin{array}{l}\text { 洛仑兹 } \\
\mid l u o^{4} \operatorname{lun}^{2} \mathrm{zi}^{1}\end{array}$ & Lorentz & $\begin{array}{l}\text { 慕尼黑 } \\
\mathrm{mu}^{4} \mathrm{ni}^{2} \mathrm{hei}^{1}\end{array}$ & Munich \\
\hline T4T2T2 & $\begin{array}{l}\text { 不来梅 } \\
\mathrm{bu}^{4} \mathrm{lai}^{2} \mathrm{mei}^{2}\end{array}$ & Bremen & $\begin{array}{l}\text { 布隆迪 } \\
\mathrm{bu}^{4} \text { long }^{2} \mathrm{di}^{2}\end{array}$ & Burundi \\
\hline T4T2T3 & $\begin{array}{l}\text { 洛伦佐 } \\
\text { luo }^{4} \text { lun }^{2} \mathrm{zuo}^{3}\end{array}$ & Lorenzo & $\begin{array}{l}\text { 立陶宛 } \\
\mathrm{li}^{4} \operatorname{tao}^{2} \operatorname{wan}^{3}\end{array}$ & Lithuania \\
\hline T4T2T4 & $\begin{array}{l}\text { 奥兰治 } \\
\mathrm{ao}^{4} \operatorname{lan}^{2} \mathrm{zhi}^{4}\end{array}$ & Orange & $\begin{array}{l}\text { 克林顿 } \\
\mathrm{ke}^{4} \operatorname{lin}^{2} \mathrm{dun}^{4}\end{array}$ & Clinton \\
\hline T4T4T1 & $\begin{array}{l}\text { 洛佩兹 } \\
\mid l u o^{4} \mathrm{pei}^{4} \mathrm{zi}^{1}\end{array}$ & Lopez & $\begin{array}{l}\text { 鹿特丹 } \\
\mathrm{lu}^{4} \mathrm{te}^{4} \mathrm{dan}^{1}\end{array}$ & Rotterdam \\
\hline T4T4T2 & $\begin{array}{l}\text { 拜占庭 } \\
\text { bai }^{4} \text { zhan }^{4} \text { ting }^{2}\end{array}$ & Byzantium & $\begin{array}{l}\text { 密克罗 } \\
\mathrm{mi}^{4} \mathrm{ke}^{4} \text { luo }^{2}\end{array}$ & Mikro \\
\hline T4T4T3 & $\begin{array}{l}\text { 瑞贝卡 } \\
\text { rui }^{4} \text { bei }^{4} \text { ka }^{3}\end{array}$ & Rebecca & $\begin{array}{l}\text { 洛丽塔 } \\
\mathrm{luo}^{4} \mathrm{li}^{4} \mathrm{ta}^{3}\end{array}$ & Lolita \\
\hline T4T4T4 & $\begin{array}{l}\text { 奥地利 } \\
\mathrm{ao}^{4} \mathrm{di}^{4} \mathrm{li}^{4}\end{array}$ & Austria & $\begin{array}{l}\text { 意大利 } \\
\mathrm{yi}^{4} \mathrm{da}^{4} \mathrm{li}^{4}\end{array}$ & Italy \\
\hline
\end{tabular}

Trisyllabic list 2: $\sigma \sigma+\sigma$

\begin{tabular}{|c|c|c|c|c|}
\hline Tonal sequences & Word 1 & & Word 2 & \\
\hline T1T1T1 & $\begin{array}{l}\text { 拖拉机 } \\
\text { tuo }{ }^{1} \mathrm{la}^{1} \mathrm{ji}^{1}\end{array}$ & tractor & $\begin{array}{l}\text { 出租车 } \\
\text { chu }^{1} z u^{1} \text { che }^{1}\end{array}$ & taxi \\
\hline T1T1T2 & $\begin{array}{l}\text { 公安局 } \\
\text { gong }^{1} \mathrm{an}^{1} \mathrm{ju}^{2}\end{array}$ & police station & $\begin{array}{l}\text { 工商局 } \\
\text { gong }^{1} \text { shang }^{1} \text { ju}^{2}\end{array}$ & Trade and Industry Bureau \\
\hline T1T1T3 & $\begin{array}{l}\text { 拉丁舞 } \\
\mathrm{la}^{1} \mathrm{ding}^{1} \mathrm{wu}^{3}\end{array}$ & Latin dance & $\begin{array}{l}\text { 飞机场 } \\
\text { fei }^{1} \mathrm{ji}^{1} \text { chang }^{3}\end{array}$ & airport \\
\hline T1T1T4 & $\begin{array}{l}\text { 基督教 } \\
\mathrm{ji}^{1} \mathrm{du}^{1} \mathrm{jiao}^{4}\end{array}$ & Christianity & $\begin{array}{l}\text { 夫妻店 } \\
f u^{1} \mathrm{qi}^{1} \mathrm{dian}^{4}\end{array}$ & family-run shop \\
\hline T1T2T1 & $\begin{array}{l}\text { 金鱼缸 } \\
\mathrm{jin}^{1} \mathrm{yu}^{2} \mathrm{gang}^{1}\end{array}$ & goldfish tank & $\begin{array}{l}\text { 天狼星 } \\
\operatorname{tian}^{1} \text { lang }^{2} \text { xing }^{1}\end{array}$ & Sirius \\
\hline T1T2T2 & 乌龙球 & own goal & 安全局 & Security Bureau \\
\hline
\end{tabular}




\begin{tabular}{|c|c|c|}
\hline 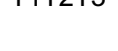 & cong $^{1}$ you $^{2}$ bing $^{3}$ & \\
\hline T1T2T4 & $\begin{array}{l}\text { 资格证 } \\
\text { zi }^{1} \text { ge }^{2} \text { zheng }^{4}\end{array}$ & certificate \\
\hline T1T3T1 & $\begin{array}{l}\text { 资本家 } \\
\mathrm{zi}^{1} \mathrm{ben}^{3} \mathrm{jia}^{1}\end{array}$ & capitalist \\
\hline Т1Т3Т2 & $\begin{array}{l}\text { 宗主国 } \\
\text { zong }^{1} \text { zhu }^{3} \text { guo }^{2}\end{array}$ & suzerain \\
\hline Т1Т3Т3 & $\begin{array}{l}\text { 斑点狗 } \\
\text { ban }^{1} \text { dian }^{3} \mathrm{gou}^{3}\end{array}$ & Dalmatian dog \\
\hline T1T3T4 & $\begin{array}{l}\text { 天主教 } \\
\operatorname{tian}^{1} \mathrm{zhu}^{3} \mathrm{jiao}^{4}\end{array}$ & Catholicism \\
\hline T1T4T1 & $\begin{array}{l}\text { 音乐家 } \\
\text { yin }^{1} \mathrm{yue}^{4} \mathrm{jia}^{1}\end{array}$ & musician \\
\hline T1T4T2 & $\begin{array}{l}\text { 机器人 } \\
\mathrm{ji}^{1} \mathrm{qi}^{4} \text { ren }^{2}\end{array}$ & robot \\
\hline T1T4T3 & $\begin{array}{l}\text { 登记表 } \\
\text { deng }^{1} \mathrm{ji}^{4} \text { biao }^{3}\end{array}$ & registration form \\
\hline T1T4T4 & $\begin{array}{l}\text { 关帝庙 } \\
\text { guan }^{1} \mathrm{di}^{4} \mathrm{miao}^{4}\end{array}$ & Temple of General Kuan \\
\hline T2T1T1 & $\begin{array}{l}\text { 楼梯间 } \\
\operatorname{lou}^{2} \mathrm{ti}^{1} \mathrm{jian}^{1}\end{array}$ & stairwell \\
\hline T2T1T2 & $\begin{array}{l}\text { 鱼肝油 } \\
\mathrm{yu}^{2} \mathrm{gan}^{1} \mathrm{you}^{2}\end{array}$ & fish oil \\
\hline T2T1T3 & $\begin{array}{l}\text { 服装厂 } \\
\text { fu }^{2} \text { zhuang } \\
\end{array}$ & garment factory \\
\hline T2T1T4 & $\begin{array}{l}\text { 牙周病 } \\
\mathrm{ya}^{2} \text { zhou }^{1} \text { bing }^{4}\end{array}$ & periodontal disease \\
\hline T2T2T1 & $\begin{array}{l}\text { 南极洲 } \\
\text { nan }^{2} \mathrm{ji}^{2} \mathrm{zhou}^{1}\end{array}$ & Antarctica \\
\hline Т2Т2Т2 & $\begin{array}{l}\text { 蝴蝶结 } \\
h u^{2} \mathrm{die}^{2} \mathrm{jie}^{2}\end{array}$ & bow knot \\
\hline T2T2T3 & $\begin{array}{l}\text { 篮球场 } \\
\operatorname{lan}^{2} \text { qiu }^{2} \text { chang }^{3}\end{array}$ & basketball court \\
\hline Т2Т2Т4 & $\begin{array}{l}\text { 能源部 } \\
\text { neng }^{2} \mathrm{yuan}^{2} \mathrm{bu}^{4}\end{array}$ & Ministry of Energy \\
\hline T2Т3Т1 & $\begin{array}{l}\text { 平板车 } \\
\text { ping }^{2} \text { ban }^{3} \text { che }^{1}\end{array}$ & trolley \\
\hline Т2Т3Т2 & $\begin{array}{l}\text { 龙井茶 } \\
\text { long }^{2} \text { jing }^{3} \text { cha }^{2}\end{array}$ & Longjing tea \\
\hline Т2Т3Т3 & $\begin{array}{l}\text { 长短腿 } \\
\text { chang }^{2} \text { duan }^{3} \text { tui }^{3}\end{array}$ & leg length discrepancy \\
\hline T2Т3Т4 & $\begin{array}{l}\text { 营养液 } \\
\text { ying }^{2} \text { yang }^{3} y^{4}\end{array}$ & nutrient \\
\hline T2T4T1 & $\begin{array}{l}\text { 杂技班 } \\
\mathrm{za}^{2} \mathrm{ji}^{4} \mathrm{ban}^{1}\end{array}$ & acrobatic team \\
\hline T2T4T2 & $\begin{array}{l}\text { 国庆节 } \\
\text { guo }^{2} \text { qing }^{4} \mathrm{jie}^{2}\end{array}$ & National Day \\
\hline T2T4T3 & $\begin{array}{l}\text { 游乐场 } \\
\text { you }^{2} \mathrm{le}^{4} \text { chang }^{3}\end{array}$ & playground \\
\hline T2T4T4 & $\begin{array}{l}\text { 疾病册 } \\
\mathrm{ji}^{2} \text { bing } \mathrm{ce}^{4}\end{array}$ & list of diseases \\
\hline T3T1T1 & $\begin{array}{l}\text { 闪光灯 } \\
\text { shan }^{3} \text { guang }^{1} \text { deng }^{1}\end{array}$ & flash light \\
\hline Т3Т1Т2 & $\begin{array}{l}\text { 火车头 } \\
\text { huo }^{3} \text { che }^{1} \text { tou }^{2}\end{array}$ & locomotive \\
\hline T3T1T3 & $\begin{array}{l}\text { 奖金卡 } \\
\text { jiang }^{3} \mathrm{jin}^{1} \mathrm{ka}^{3}\end{array}$ & bonus card \\
\hline T3Т1T4 & $\begin{array}{l}\text { 火车票 } \\
\text { huo }^{3} \text { che }^{1} \text { piao }^{4}\end{array}$ & train ticket \\
\hline Т3Т2Т1 & $\begin{array}{l}\text { 主人翁 } \\
\text { zhu }^{3} \text { ren }^{2} \text { weng }^{1}\end{array}$ & hero \\
\hline Т3Т2Т2 & $\begin{array}{l}\text { 狗头铡 } \\
\text { gou }^{3} \text { tou }^{2} \mathrm{zha}^{2}\end{array}$ & kobold guillotine \\
\hline Т3Т2Т3 & 打折卡 & coupon \\
\hline
\end{tabular}

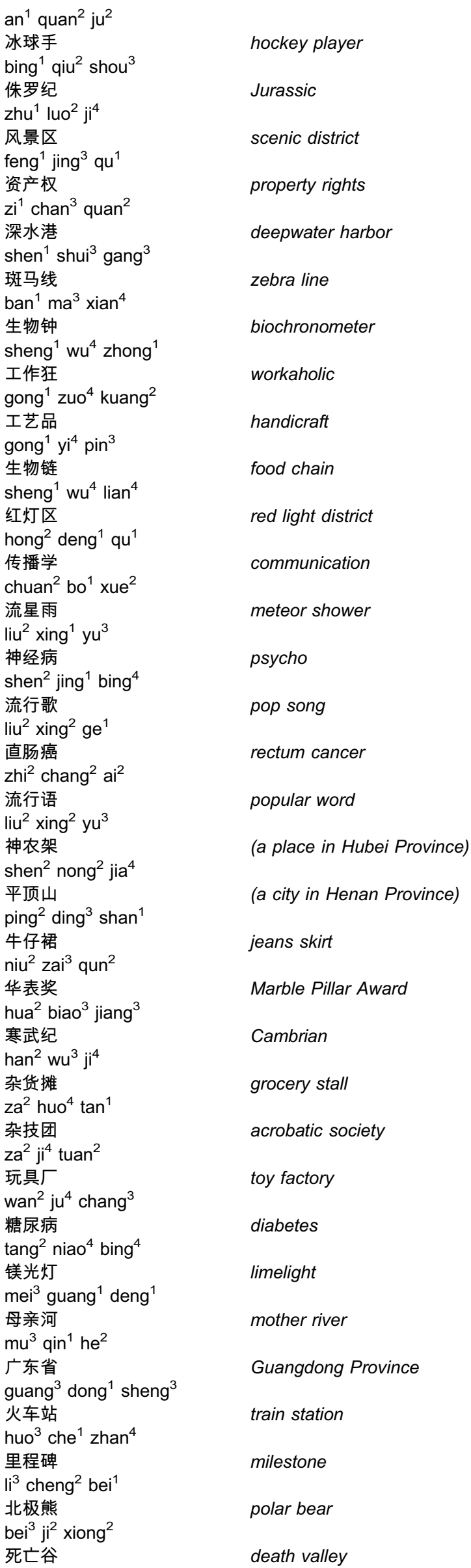




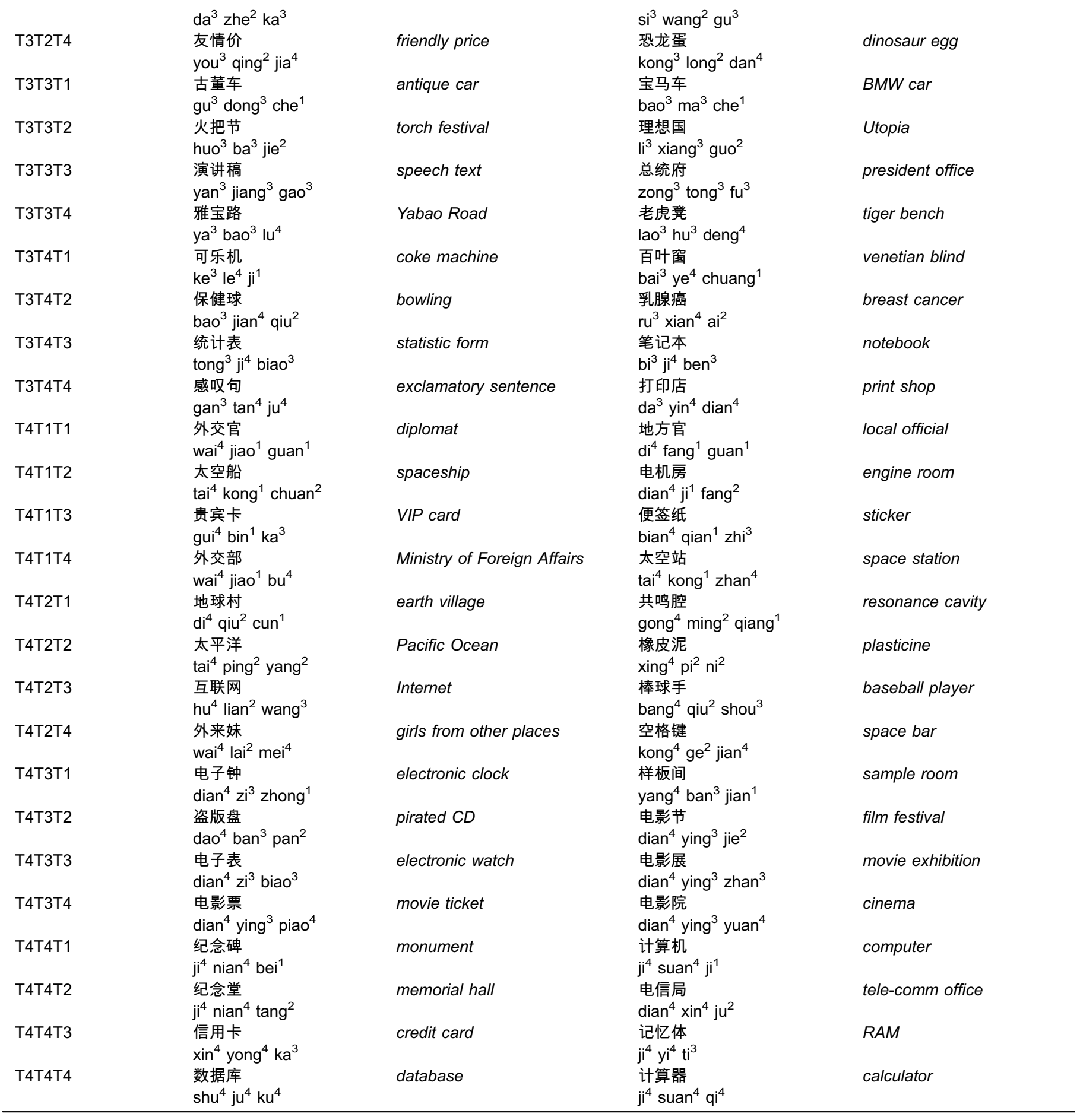

Trisyllabic list 3: $\sigma+\sigma \sigma$

\begin{tabular}{|c|c|c|c|c|}
\hline Tonal sequences & Word 1 & & Word 2 & \\
\hline T1T1T1 & $\begin{array}{l}\text { 高工资 } \\
\text { gao }^{1} \text { gong }^{1} z^{1}\end{array}$ & high salary & $\begin{array}{l}\text { 新飞机 } \\
\operatorname{xin}^{1} \mathrm{fei}^{1} \mathrm{ji}^{1}\end{array}$ & new aircraft \\
\hline T1T1T2 & $\begin{array}{l}\text { 新中国 } \\
\text { xin }^{1} \text { zhong }^{1} \text { guo }^{2}\end{array}$ & new China & $\begin{array}{l}\text { 多功能 } \\
\text { duo }^{1} \text { gong }^{1} \text { neng }^{2}\end{array}$ & multi-function \\
\hline T1T1T3 & $\begin{array}{l}\text { 宽肩膀 } \\
\text { kuan }^{1} \text { jian }^{1} \text { bang }^{3}\end{array}$ & wide shoulder & $\begin{array}{l}\text { 光污染 } \\
\text { guang }{ }^{1} \mathrm{wu}^{1} \mathrm{ran}^{3}\end{array}$ & light pollution \\
\hline T1T1T4 & $\begin{array}{l}\text { 轻音乐 } \\
\text { qing }^{1} \mathrm{yin}^{1} \mathrm{yue}^{4}\end{array}$ & light music & $\begin{array}{l}\text { 新花样 } \\
\text { xin }^{1} \text { hua }^{1} \text { yang }^{4}\end{array}$ & new trick \\
\hline
\end{tabular}


T1T2T1

$\mathrm{T} 1 \mathrm{~T} 2 \mathrm{~T} 2$

T1T2T3

T1T2T4

T1T3T1

T1T3T2

T1T3T3

T1T3T4

T1T4T1

T1T4T2

T1T4T3

T1T4T4

T2T1T1

T2T1T2

T2T1T3

T2T1T4

T2T2T1

T2T2T2

T2T2T3

T2T2T4

T2T3T1

T2T3T2

T2Т3T3

T2T3T4

T2T4T1

T2T4T2

T2T4T3

T2T4T4

T3T1T1

T3T1T2

T3T1T3

T3T1T4

T3T2T1
干蹄筋

gan $^{1} \mathrm{ti}^{2} \mathrm{jin}^{1}$

东柏林

dong ${ }^{1} \mathrm{bo}^{2} \mathrm{lin}^{2}$

新油桶

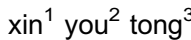

新邮件

$\operatorname{xin}^{1}$ you $^{2}$ jian $^{4}$

湿纸巾

shi $^{1} \mathrm{zhi}^{3} \mathrm{jin}^{1}$

猪口条

$\mathrm{zhu}^{1} \mathrm{kou}^{3} \mathrm{tiao}^{2}$

新总统

xin $^{1}$ zong $^{3}$ tong $^{3}$

亲姐妹

qin $^{1} \mathrm{jie}^{3} \mathrm{mei}^{4}$

湿面巾

$\mathrm{shi}^{1} \operatorname{mian}^{4} \mathrm{jin}^{1}$

猪大肠

$\mathrm{zhu}^{1} \mathrm{da}^{4}$ chang $^{2}$

新电影

$\operatorname{xin}^{1} \operatorname{dian}^{4}$ ying $^{3}$

新概念

$\operatorname{xin}^{1}$ gai $^{4}$ nian $^{4}$

团中央

tuan $^{2}$ zhong $^{1}$ yang ${ }^{1}$

红蜻蜓

hong $^{2}$ qing $^{1}$ ting $^{2}$

红糙米

hong ${ }^{2} \mathrm{cao}^{1} \mathrm{mi}^{3}$

咸鸭蛋

$x a^{2} y^{1}$ dan $^{4}$

蓝瓷砖

$\operatorname{lan}^{2} \mathrm{ci}^{2}$ zhuan $^{1}$

前王朝

qian $^{2}$ wang $^{2}$ chao $^{2}$

毒苹果

$\mathrm{du}^{2}$ ping $^{2}$ guo $^{3}$

咸白菜

xian ${ }^{2}$ bai $^{2}$ cai $^{4}$

纯酒精

chun $^{2} \mathrm{jiu}^{3} \mathrm{jing}^{1}$

红嘴唇

hong $^{2}$ zui $^{3}$ chun $^{2}$

前总统

qian $^{2}$ zong $^{3}$ tong $^{3}$

蓝孔雀

$\operatorname{lan}^{2}$ kong $^{3}$ que $^{4}$

男卫兵

nan $^{2}$ wei $^{4}$ bing

红气球

hong ${ }^{2} \mathrm{qi}^{4} \mathrm{qiu}^{2}$

源代码

yuan $^{2}$ dai $^{4} \mathrm{ma}^{3}$

全自动

quan $^{2} \mathrm{zi}^{4}$ dong $^{4}$

假观音

$\mathrm{jia}^{3}$ guan $^{1}$ yin $^{1}$

小家庭

xiao $^{3}$ jia $^{1}$ ting $^{2}$

伪君子

wei $^{3}$ jun $^{1} z^{3}$

冷空气

leng ${ }^{3}$ kong $^{1}$ qi $^{4}$

假投资

$\mathrm{jia}^{3}$ tou $^{2} \mathrm{zi}^{1}$ dry tendon

East Berlin

new oil tank

new mail

wet tissue

pig tongue

new president

blood sister

wet facial tissue

pig intestine

new movie

new concept

league center

red dragonfly

red rice

salty duck egg

blue ceramic tile

previous dynasty

toxic apple

salty cabbage

pure alcohol

red lip

former president

blue peacock

male guard

red balloon

source code

automatic

fake Buddha

small family

hypocrite

cold air

fake investment
双职工

shuang ${ }^{1} \mathrm{zhi}^{2}$ gong ${ }^{1}$

西柏林

$x i^{1} b o^{2} \operatorname{lin}^{2}$

鲜牛奶

xian ${ }^{1} \mathrm{niu}^{2} \mathrm{nai}^{3}$

新词汇

$\mathrm{xin}^{1} \mathrm{Ci}^{2} \mathrm{hui}^{4}$

清辅音

qing $^{1} \mathrm{fu}^{3} \mathrm{yin}^{1}$

金耳环

jin $^{1} \mathrm{er}^{3}$ huan $^{2}$

新产品

$\operatorname{xin}^{1} \operatorname{chan}^{3} \operatorname{pin}^{3}$

新产业

$\operatorname{xin}^{1}$ chan $^{3} y e^{4}$

新校区

$\mathrm{xin}^{1} \mathrm{xiao}^{4} \mathrm{qu}^{1}$

新纪元

$\operatorname{xin}^{1} \mathrm{ji}^{4}$ yuan $^{2}$

花大姐

hua $^{1} \mathrm{da}^{4} \mathrm{jie}^{3}$

中世纪

zhong $^{1} \mathrm{shi}^{4} \mathrm{ji}^{4}$

毛蜘蛛

$\mathrm{mao}^{2} \mathrm{zhi}^{1} \mathrm{zhu}^{1}$

瓷花瓶

$\mathrm{ci}^{2}$ hua $^{1}$ ping $^{2}$

零增长

ling $^{2}$ zeng $^{1}$ zhang $^{3}$

皮车座

$\mathrm{pi}^{2} \mathrm{che}^{1} \mathrm{zuo}^{4}$

男同胞

nan $^{2}$ tong $^{2}$ bao $^{1}$

明长城

ming $^{2}$ chang $^{2}$ cheng $^{2}$

男旗手

nan $^{2} \mathrm{qi}^{2}$ shou $^{3}$

雌杨树

$\mathrm{ci}^{2}$ yang $^{2}$ shu $^{4}$

浊辅音

zhuo $^{2} \mathrm{fu}^{3} \mathrm{yin}^{1}$

蓝宝石

$\operatorname{lan}^{2} \mathrm{bao}^{3} \mathrm{shi}^{2}$

男保姆

$\mathrm{nan}^{2} \mathrm{bao}^{3} \mathrm{mu}^{3}$

雌孔雀

$\mathrm{ci}^{2}$ kong $^{3}$ que $^{4}$

白衬衫

bai $^{2}$ chen $^{4}$ shan $^{1}$

南半球

nan $^{2}$ ban $^{4} \mathrm{qiu}^{2}$

红墨水

hong ${ }^{2} \mathrm{mo}^{4}$ shui $^{3}$

全世界

quan ${ }^{2} \mathrm{shi}^{4} \mathrm{jie}^{4}$

党中央

dang $^{3}$ zhong $^{1}$ yang $^{1}$

紫蜻蜓

$\mathrm{zi}^{3}$ qing $^{1}$ ting $^{2}$

水污染

shui ${ }^{3} \mathrm{wu}^{1} \mathrm{ran}^{3}$

总司令

zong $^{3} \mathrm{si}^{1}$ ling $^{4}$

假结婚

$\mathrm{jia}^{3} \mathrm{jie}^{2}$ hun $^{1}$ working parents

west Berlin

fresh milk

new vocabulary

voiceless consonant

gold earring

new product

new industry

new campus

new era

ladybug

middle age

hairy spider

ceramic vase

zero increase

feather seat

fellow men

Ming

Great Wall

male

flag-bearer

female poplar

voiced

consonant

sapphire

male nanny

female peacock

white shirt

south hemisphere

red ink

entire world

party center

purple dragonfly

water pollution

general commander

fake marriage 


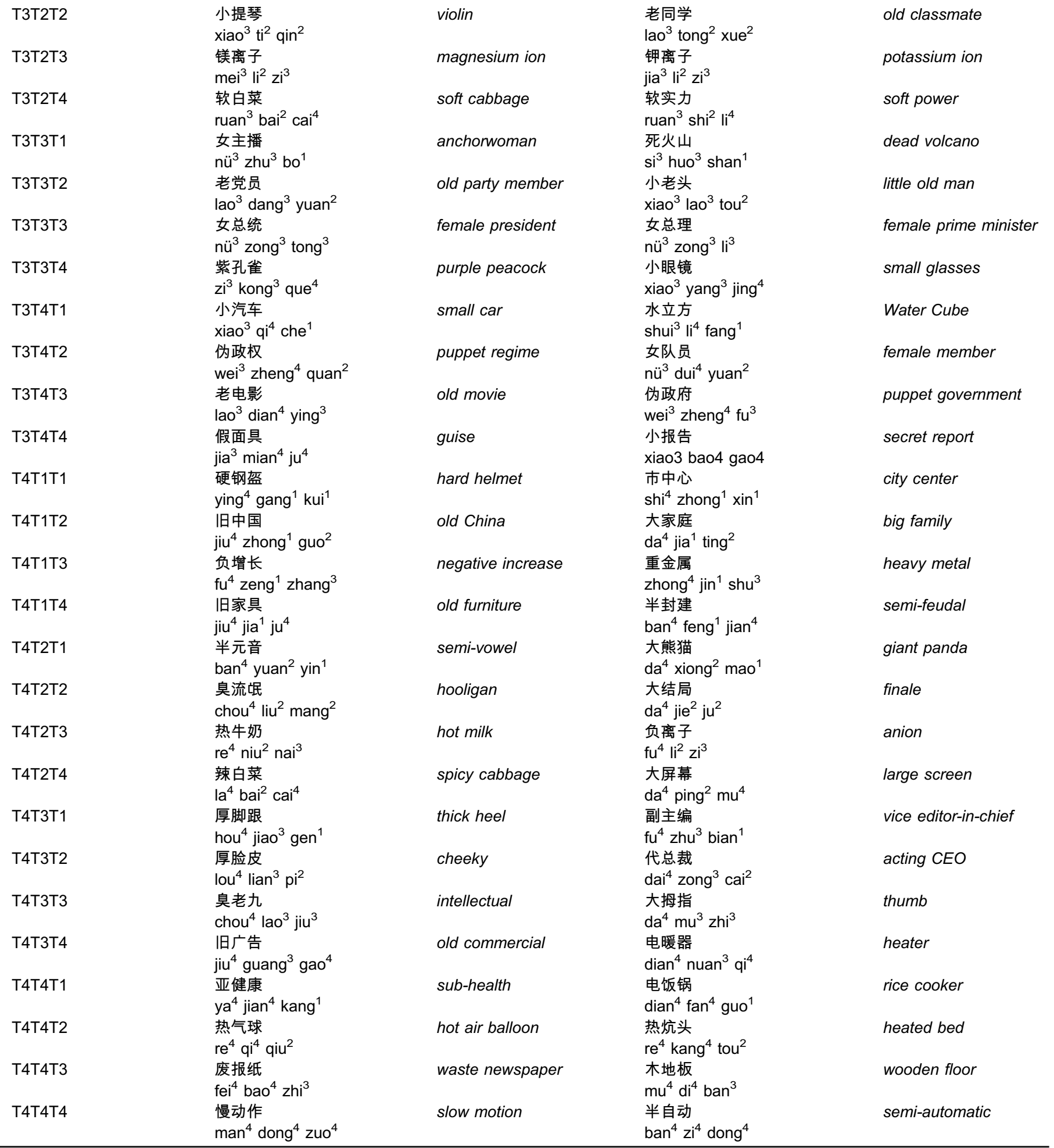

\section{References}

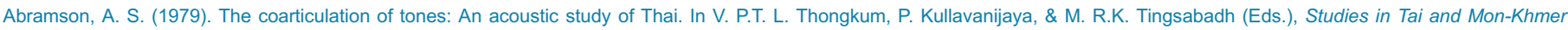
phonetics and phonology: In honour of Eugenie Henderson (pp. 1-16). Bangkok: Chulalongkorn University Press.

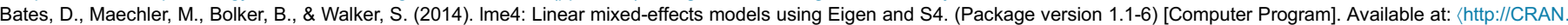
R-project.org/package $=|m e 4\rangle$.

Boersma, P. \& Weenink, D. (2011). Praat: Doing phonetics by computer. (Version 5.2.36) [Computer Program]. Available at: 〈http://www.fon.hum.uva.nl/praat/〉.

Brunelle, M. (2009). Northern and southern Vietnamese tone coarticulation: A comparative case study. Journal of the Southeast Asian Linguistics Society, 1, 49-62.

Chang, Y.-C., \& Hsieh, F.-F. (2012). Tonal coarticulation in Malaysian Hokkien: A typological anomaly?. The Linguistic Review, $29,37-73$.

Chao, Y.-R. (1968). A grammar of spoken Chinese. Berkeley: University of California Press. 
Chen, M. Y. (2000). Tone sandhi: Patterns across Chinese dialects. Cambridge: Cambridge University Press.

Chen, Y. (2010). Post-focus fo compression - now you see it, now you don't. Journal of Phonetics, 38, 517-525.

Chen, Y. (2012). Tonal variation. In A. C. Cohn, C. Fougeron, \& M. K. Huffman (Eds.), The Oxford handbook of laboratory phonology (pp. 103-114). Oxford: Oxford University Press.

Chen, Y., \& Xu, Y. (2006). Production of weak elements in speech-Evidence from f0 patterns of neutral tone in Standard Chinese. Phonetica, 63, 47-75.

Chen, Y., \& Gussenhoven, C. (2008). Emphasis and tonal implementation in Mandarin Chinese. Journal of Phonetics, 36, $724-746$.

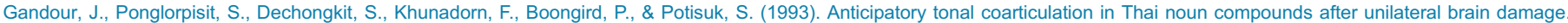
Brain and Language, 45, 1-20.

Gandour, J., Potisuk, S., \& Dechongkit, S. (1994). Tonal coarticulation in Thai. Journal of Phonetics, 22, 477-492.

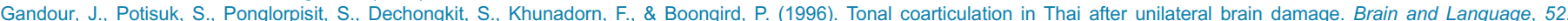
505-535.

Tianjin fangyan [Tianjin Mandarin]. In G. Han (Ed.), Beijing: Beijing Yanshan Press.

Han, M. S., \& Kim, K.-O. (1974). Phonetic variation of Vietnamese tones in disyllabic utterances. Journal of Phonetics, 2, $223-232$.

Hothorn, T., Bretz, F. \& Westfall, P. (2008). Simultaneous inference in general parametric models. Biometrical Journal, 50, 346-363.

Hung, T.-N. (1987). Tianjin tone sandhi: Towards a unified approach. Journal of Chinese Linguistics, 15, 274-305.

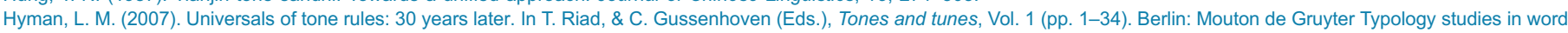
and sentence prosody.

Kochanski, G., Shih, C., \& Jing, H. (2003). Hierarchical structure and word strength prediction of Mandarin prosody. International Journal of Speech Technology, 6, 33-43.

$\mathrm{Li}, \mathrm{Q}$., \& Chen, Y. (2012). Trisyllabic tone sandhi in Tianjin Mandarin. In Proceedings of the third international symposium on tonal aspects of languages. Nanjing, China.

Li, X., \& Liu, S. (1985). Tianjin fangyan de liandu biandiao [Tone sandhi in Tianjin Mandarin]. Zhongguo Yuwen, 1, 76-80.

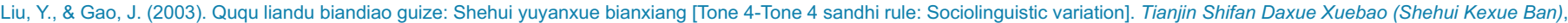
$5,65-69$.

Lu, J. (1997). Tianjin fangyan zhong de yizhong xinde liandu biandiao [A new tone sandhi rule in Tianjin Mandarin]. Tianjin Shida Xuebao, 4, 67-72.

Ma, Q. (2005). "Tianjinhua liandu biandiao zhi mi" de youxuanlun jieshi [The optimality account of "the mysterious Tianjin tone sandhi"]. Zhongguo Yuwen, 6, 561-568.

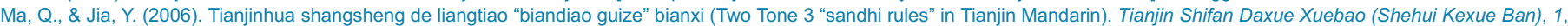
53-58.

Mei, T.-L. (1977). Tones and tone sandhi in 16th century Mandarin. Journal of Chinese Linguistics, 5, 237-260.

Mirman, D. (2014). Growth curve analysis and visualization using R. Boca Raton: CRC Press.

Palmer, A. (1969). Thai tone variants and the language teachers. Language Learning-A Journal of Applied Linguistics, 19, $287-299$.

Peng, S.-H. (1997). Production and perceptioin of Taiwanese tones in different tonal and prosodic contexts. Journal of Phonetics, 25, 371-400.

Potisuk, S., Gandour, J., \& Harper, M. P. (1997). Contexual variation in trisyllabic sequences of Thai tones. Phonetica, 54, $22-42$.

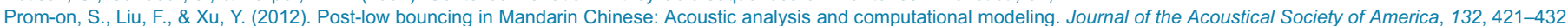

R Core Team. (2014). R: A language and environment for statistical computing. (Version 3.1.0) [Computer Program]. Available at: 〈http://www.R-project.org/〉.

Rose, P. (1987). Considerations in the normalisation of the fundamental frequency of linguistic tone. Speech Communication, 6, 343-352.

Scholz, F. (2012). Tone sandhi, prosodic phrasing, and focus marking in Wenzhou Chinese (Ph.D. dissertation). Leiden: Leiden University.

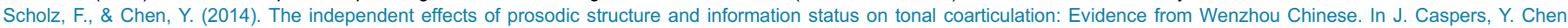

W. Heeren, J. Pacilly, N. O. Schiller, \& E. van Zanten (Eds.), Above and beyond the segments: Experimental linguistics and phonetics (pp. 275-287). John Benjamins Publishing Company.

Shen, X. S. (1990). Tonal coarticulation in Mandarin. Journal of Phonetics, 18, 281-295.

Shen, X. S. (1992). On tone sandhi and tonal coarticulation. Acta Linguistica Hafniensia: International Journal of Linguistics, $25,83-94$.

Shi, F. (1986). Tianjin fangyan shuangzizu shengdiao fenxi [Analysis of disyllabic tones in Tianjin Mandarin]. Yuyan Yanjiu, 1, 77-90.

Shih, C.-L. (1986). The prosodic domain of tone sandhi in Chinese (Ph.D. dissertation). San Diego: University of California, San Diego.

Shih, C.-L. \& Konchanski, G. P. (2000). Chinese tone modeling with Stem-ML. In Proceedings of the international conference on spoken language processing. Beijing.

Tan, F. (1987). Tone sandhi in the Tianjin dialect. Journal of Chinese Linguistics, 15, 228-246.

Wang, H. S. (2002). The prosodic effects on Taiwan Min tones. Language and Linguistics, 3, 839-852.

Wang, J. (2002). Youxuanlun he tianjinhua de liandu biandiao ji qingsheng [Optimality theory and tone sandhi and neutral tone in Tianjin Manadrin]. Zhongguo Yuwen, 4, 363-372.

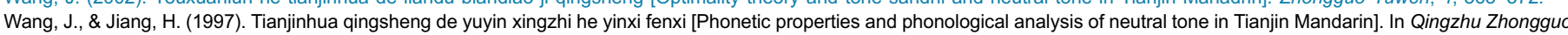
Shehui Kexueyuan Yuyan Yanjiusuo Jainsuo 45 Zhounian Xueshu Lunwenji. Beijing: Chinese Academy of Social Sciences.

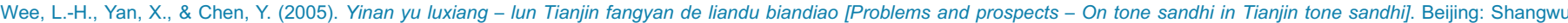
Press.

Wu, Z. (1985). Putonghua sanzizu biandiao guilü (Rules of trisyllabic tone sandhi in Standard Chinese). Zhongguo Yuyan Xuebao, 2.

Xu, Y. (1994). Production and perception of coarticulated tones. Journal of the Acoustical Society of America, 95, 2240-2253.

Xu, Y. (1997). Contextual tonal variations in Mandarin. Journal of Phonetics, 25, 61-83.

$\mathrm{Xu}, \mathrm{Y}$. (1999). Effects of tone and focus on the formation and alignment of fO contours. Journal of Phonetics, 27, 55-105.

$\mathrm{Xu}, \mathrm{Y}$. (2001). Sources of tonal variations in connected speech. Journal of Chinese Linguistics, Monograph Series, 17, 1-31

Yu, A. C. L. (2007). Understanding near mergers: The case of morphological tone in Cantonese. Phonology, 24, $187-214$.

Zhang, J. (2010). Issues in the analysis of Chinese tone. Language and Linguistics Compass, 4, 1137-1153.

Zhang, J. \& Liu, J. (2010). Patterns of tone sandhi productivity in Tianjin Chinese. In Proceedings of 160th meeting acoustical society of america. Cancun, Mexico.

Zhang, J., \& Liu, J. (2011). Tone sandhi and tonal coarticulation in Tianjin Chinese. Phonetica, 68, 161-191.

Zhang, Z.-s (1987). The paradox of Tianjin: Another look. Journal of Chinese Linguistics, 15, 228-246.

Zsiga, E., \& Nitisaroj, R. (2007). Tone features, tone perception, and peak alignment in Thai. Language and Speech, 50, 343-383. 